\title{
Does Asymmetric Information Drive Capital Structure Decisions?
}

\author{
Sreedhar T. Bharath \\ Department of Finance, Ross School of Business, University of Michigan
}

Paolo Pasquariello

Department of Finance, Ross School of Business, University of Michigan

Guojun Wu

Department of Finance, C. T. Bauer School of Business, University of Houston

\begin{abstract}
Using a novel information asymmetry index based on measures of adverse selection developed by the market microstructure literature, we test whether information asymmetry is an important determinant of capital structure decisions, as suggested by the pecking order theory. Our index relies exclusively on measures of the market's assessment of adverse selection risk rather than on ex ante firm characteristics. We find that information asymmetry does affect the capital structure decisions of U.S. firms over the sample period 1973-2002. Our findings are robust to controlling for conventional leverage factors (size, tangibility, $Q$ ratio, profitability), the sources of firms' financing needs, and such firm attributes as stock return volatility, stock turnover, and intensity of insider trading. For example, we estimate that on average, for every dollar of financing deficit to cover, firms in the highest adverse selection decile issue 30 cents of debt more than firms in the lowest decile. Overall, this evidence explains why the pecking order theory is only partially successful in explaining all of firms' capital structure decisions. It also suggests that the theory finds support when its basic assumptions hold in the data, as should reasonably be expected of any theory. (JEL G32)
\end{abstract}

\footnotetext{
We are grateful to Stewart Myers (our NBER discussant), Matt Spiegel (the Editor), and three anonymous referees for their valuable insights. We also thank Viral Acharya, Andres Almazan, Yakov Amihud, Murray Frank, Sudip Gupta, M.P. Narayanan, Norman Schürhoff, Pei Shao, Avanidhar Subrahmanyam, Ramon Uppal, Ivo Welch, and Jaime Zender for useful discussions, and seminar participants at the University of Michigan, Washington University (St. Louis), the 2005 FRA conference, the 2006 NBER Corporate Finance meetings, the 2006 FIRS conference, the 2006 EFA meetings, the 2006 CRSP Forum, the 2006 CAF Winter Research Conference, and the 2008 AFA meetings for comments. Lastly, we thank the Ross School of Business Dean's Research Fund for financial support and Kenneth French and Soren Hvidkjaer for providing financial data. Send correspondence to either Sreedhar T. Bharath, Department of Finance, Ross School of Business, University of Michigan, Suite E7606, Ann Arbor, MI 48109; telephone: (734) 763-0485. E-mail: sbharath@umich.edu; Paolo Pasquariello, Department of Finance, Ross School of Business, University of Michigan, Suite E7602, Ann Arbor, MI 48109; telephone: (734) 764-9286. E-mail: ppasquar@bus.umich.edu; or Guojun Wu, Department of Finance, C. T. Bauer School of Business, University of Houston, Suite 220F, Houston, TX 77204; telephone: (713) 743-4813. E-mail: gwu2@uh.edu.
}

(C) The Author 2008. Published by Oxford University Press on behalf of The Society for Financial Studies. All rights reserved. For Permissions, please e-mail: journals.permissions@oxfordjournals.org. 


\section{Introduction}

The problem of explaining firms' capital structure is intensely debated in corporate finance. One of the most popular models of corporate financing decisions in the literature is the pecking order theory of Myers (1984). It is based on the argument in Myers and Majluf (1984) that asymmetric information problems drive the capital structure of firms. Myers (1984) argues that if managers know more than the rest of the market about their firm's value (information asymmetry), the market penalizes the issuance of securities (like equity) whose expected payoffs are crucially related to the assessment of such a value. Therefore, the pecking order theory predicts that companies should use stock issuances to cover financing deficits only as a last resort, after cheaper, less informationsensitive alternatives (like internal cash, bank debt, or public debt) have been exhausted.

Tests of the pecking order theory have focused on this main prediction of the model. Shyam-Sunder and Myers (1999) conclude that the pecking order offers a good approximation to firms' financing behavior. Their inference is challenged by Fama and French (2002); and Frank and Goyal (2003). Lemmon and Zender (2004) counter this challenge by controlling for the value of maintaining financial slack for future investment and to avoid financial distress. Yet, Leary and Roberts (2004) incorporate financial slack in their explicit analysis of the hierarchy of financing policies generated by the pecking order theory and do not find support for it. In short, the existing evidence on the pecking order is mixed.

In sharp contrast to those studies, in this article we do not seek to test the predictions of the pecking order theory. Instead, we evaluate its core assumptioni.e., information asymmetry as the determinant of capital structure decisions. ${ }^{1}$ As Fama and French (2005) observe, ultimately the pecking order theory posits that information asymmetry is an important (or perhaps even the sole) determinant of firms' capital structure. However, no test has ever been performed to ascertain the empirical viability of that basic assumption of the theory. In other words, we still do not know whether information asymmetry drives firms' capital structure decisions. That is the specific question we address in this research. In particular, we study the conformity of those decisions to the pecking order theory for different degrees of information asymmetry. If the theory correctly describes the funding process of corporations, we expect this conformity to be greater the higher is the estimated intensity of perceived information asymmetry between managers and all other market participants.

The first step in our analysis is to gather information asymmetry proxies to use as cross-sectional conditioning variables. For that purpose, we consider several measures of adverse selection developed by the market microstructure literature. This represents an important innovation of our study. The pecking

1 Accordingly, Frank and Goyal (2003, p. 237) note that "it is natural to examine firms that are commonly thought to be particularly subject to adverse selection problems" when testing the pecking order theory. 
order theory of Myers (1984); and Myers and Majluf (1984) is based on adverse selection between firm managers and market participants. Market microstructure measures of information asymmetry are designed to capture adverse selection between a larger category of agents (informed traders) and the rest of the market (uninformed traders). In other words, firm managers constitute a subset of informed traders in the market who, in turn, constitute a subset of all traders in the market. Therefore, market microstructure measures of information asymmetry are (imperfect) proxies for the financial markets' perception of the information advantage held by firm insiders and the resulting adverse selection costs; and those costs are what ultimately affect the cost of issuing information-sensitive securities.

Market microstructure proxies of information asymmetry are based on the notion — set forth by an extensive theoretical literature - that market liquidity in general, and transaction costs (e.g., the bid-ask spread) in particular, consist of three primary components: order processing, inventory, and adverse selection. The latter, crucial to our analysis, compensates liquidity providers for transacting with better-informed traders and increases with the degree of information asymmetry. A number of studies develop statistical models to extract this component from existing proxies for an asset's liquidity. These models can be broken down into three groups. Within the first group, inference about adverse selection is made from the serial covariance properties of the time series of observed asset returns. Within the second group, inference about adverse selection is based on the interaction between trading volume and asset returns. Within the last group, the extent of adverse selection is gauged from the estimation of structural models of the arrival of information-based trades.

We estimate measures of information asymmetry for each of these classes of models: the adverse selection portions of both the quoted and Roll's (1984) effective bid-ask spread (as in George, Kaul, and Nimalendran 1991), the returnvolume coefficient of Llorente et al. (2002), and the probability of informed trading of Easley et al. (1996). Unfortunately, the often scarce availability of trade and quote data limits these measures' simultaneous coverage of as many companies as possible for as long as possible in the universe of U.S. firms. This is a potentially serious limitation, for Frank and Goyal (2003) show that inference about the pecking order theory is sensitive to firm-year sample size. Thus, we also compute three broader measures of stock liquidity: the price impact measure of Amihud (2002), the (Amivest) liquidity ratio of Cooper, Groth, and Avera (1985) and Amihud, Mendelson, and Lauterbach (1997), and the reversal coefficient of Pastor and Stambaugh (2003). At any point in time, the latter three measures are likely to be driven by adverse selection, yet not exclusively so. To address this issue, we form an index of adverse selection as the first principal component of either the level of or change in all of the seven proxies described above (when available).

This index has several desirable properties. First, a burgeoning literature finds its constituents to be sensitive to a wide array of potentially informative 
corporate events (e.g., earnings, dividends, M\&A, bankruptcy, or takeover announcements) and firm characteristics (e.g., opaqueness of assets, credit ratings, or ownership structure). Second, the corporate finance literature commonly measures companies' degree of information asymmetry according to ex ante firm characteristics (e.g., their relative size, growth opportunities, or tangibility of their assets). Unfortunately, these measures are often inconsistent, as well as inherently static and persistent. Our index's constituents are instead designed to capture financial markets' time-varying perception of the information advantage held by firm insiders. Fourth, and unlike our index's constituents, more dynamic proxies for adverse selection also popular in the corporate finance literature (e.g., analyst coverage, dispersion of analysts' forecasts, magnitude of earnings surprises, or residual stock return volatility) have multiple, often ad hoc interpretations. Fifth, the index displays sensible economic traits.

As important, the inference from our analysis, based on this index, is as strong as to provide ex post validation of its use. Overall, we find that our proxies for both the extent of and change in firm-level adverse selection help explain the capital structure decisions of U.S. firms between 1973 and 2002. We begin by examining the slope coefficient in a regression of change in debt against financing deficit (as in Shyam-Sunder and Myers 1999) for firms sorted each fiscal year by information asymmetry deciles from the lowest to the highest. We find that the cross-sectional variation in the response of firms' debt issuances to their financing deficits is related (in a statistically and economically significant fashion) not only to the relative severity of, but also to the change in, those firms' information asymmetry, consistent with the pecking order theory: the greater (the increase in) a firm's adverse selection costs (over the previous fiscal year), the greater the portion of its financing deficit that firm will fund through debt in the current fiscal year. For instance, we estimate that on average, for every dollar of financing deficit to cover, firms in the highest adverse selection decile issue 30 cents of debt more than firms in the lowest decile. These patterns are robust to disaggregating firms' financing deficits into its main components (dividends, real investments, and cash flow) and to controlling for size, tangibility, and the intensity of insider trading-popular alternative proxies for firm-level information asymmetry-as well as for other firm characteristics, such as $Q$ ratio, stock return volatility, and stock turnover.

Issues with the power of these tests have been raised in the literature (e.g., Chirinko and Singha 2000). We address them by employing a number of alternative testing strategies that allow us to assess more directly the importance of information asymmetry in the cross section of firms' capital structure decisions. Specifically, we estimate firm fixed effects panel regressions of the level of (or change in) firm leverage (as in Rajan and Zingales 1995; and Frank and Goyal 2003) on our adverse selection index, four conventional firm characteristics (tangibility, profitability, sales, and market-to-book ratio), insider trading, stock return volatility, and turnover (or on their first differences). We find that 
the cross-sectional variation in firms' capital structures is related to both the extent of and the change in our measures of firm-level adverse selection, the more so the greater the portion of firms' value due to assets-in-place, even after controlling for conventional leverage factors in the literature.

According to Myers (2001), the pecking order theory was originally conceived as a conditional theory relating firms' information differences to their capital structure decisions. Consistent with this interpretation, our evidence (1) explains why the pecking order is often found only partially successful in interpreting the whole of firms' debt issuance choices, and (2) shows that the pecking order performs better when its basic assumptions hold more closely in the data, as should reasonably be expected of any model.

We proceed as follows. In Section 2, we form our measure of firm-level adverse selection and comment on its properties. In Section 3, we perform several empirical tests of the pecking order theory conditional upon this measure and interpret our findings. We conclude in Section 4.

\section{Measuring Information Asymmetry}

The problem of measuring the information asymmetry about a firm's value, hence about the payoffs of its securities, has been extensively analyzed in the market microstructure literature. ${ }^{2}$ This line of research stems from Bagehot's (1971) observation that adverse selection due to the presence of better-informed traders in a financial market may affect its process of price formation. It is reasonable to believe that market players in closer touch with a firm and its business (e.g., employees, suppliers, analysts, traders) are those who possess better information about that firm and trade on it. $^{3}$ Based on this premise, market microstructure attempts to estimate the extent of information asymmetry about a firm from observed market data (quotes, bid-ask spreads, trades, and transaction prices). These efforts have caught the attention of other areas of finance, for they may help researchers identify such an intrinsically elusive concept as a firm's information environment. This has been especially the case in corporate finance. Notably, microstructure measures have been found significantly sensitive to numerous important corporate events. $^{4}$

2 See O'Hara (1995) for an extensive review.

${ }^{3}$ For example, many studies (e.g., Seyhun 1986) show that corporate insiders earn positive abnormal returns when trading in their companies' securities.

4 An incomplete list includes earnings (Lee, Mucklow, and Ready 1993), M\&A (Chae 2005), bankruptcy (Serednyakov 2002), dividend (Graham, Koski, and Loewenstein 2006), stock splits (Desai, Nimalendran, and Venkataraman 1998), bond rating (Chae 2005), and takeover (Jennings 1994) announcements, as well as analyst coverage (Brennan and Subrahmanyam 1995), the opaqueness of banking firms' assets (Flannery, Kwan, and Nimalendran 2004), firms' ownership structure (Heflin and Shaw 2000), disclosure quality (Heflin, Shaw, and Wild 2005), credit ratings (Odders-White and Ready 2006), and investment sensitivity to stock price (Chen, Goldstein, and Jiang 2007). 
Prior microstructure work suggests a number of measures of adverse selection. Most of these measures rely upon the notion that the intensity of asymmetric information about the value of an asset is an important determinant of that asset's liquidity. Yet, the concept of liquidity (the ability to trade promptly and with little or no price impact) is also intrinsically elusive and multifaceted (see Hasbrouck 2005). In addition, many of these measures are estimated with high-frequency trade and quote data, whose sparseness limits both their time series and cross-sectional use in corporate finance. Lastly, concordance across these measures is often modest (e.g., Clarke and Shastri 2001; and Hasbrouck 2005).

To address these issues, we form a composite index of adverse selection for each firm in the COMPUSTAT database within each fiscal year between 1972 and 2002. ${ }^{5}$ The firm-level index is based on the common cross-sectional variation of either the level of or the annual change in four direct measures of information asymmetry (the adverse selection component of both quoted and effective bid-ask spreads, the probability of informed trading, and the relation between daily volume and first-order return autocorrelation) and three broader measures of market liquidity (the liquidity ratio, the illiquidity ratio, and the reversal coefficient) computed mostly from CRSP data. The latter three measures are more widely available than the former four, especially over the earlier part of our sample period. Hence, they allow us to retain as many firm-year datapoints as possible from the COMPUSTAT universe. However, at any point in time, any of those liquidity measures may not be driven exclusively by adverse selection. We minimize the likelihood that these measures are connected to "noninformational" liquidity by combining them with the first four "informational" proxies into a (level or change) index based exclusively on their first principal component. Next, we describe each of those microstructure measures, the procedure for the construction of our index, and the index's basic properties. ${ }^{6}$

\subsection{Index constituents}

Most microstructure models of asymmetric information assume that betterinformed agents use their informational advantage to profit from trading. The resulting adverse selection risk induces market-makers to post quotes not only compensating them for holding undesired inventory and providing liquidity, but also offsetting their expected losses versus informed traders with gains from uninformed traders. Therefore, observed measures of market liquidity — most notably the bid-ask spread-should depend not only on inventory, transaction, and order-processing costs but also on adverse selection costs. Much research has been devoted to estimating the adverse selection component of the bid-ask

5 Following standard practice (e.g., Frank and Goyal 2003), we exclude financial firms (SIC 6000-6999), regulated utilities (SIC 4900-4999), firms involved in major mergers (COMPUSTAT footnote code AB), firms with missing book value of assets, and a small number of firms that report format codes 4,5 , or 6 .

${ }^{6}$ Further details on the estimation of these measures are available in a previous version of this paper at http://papers.ssrn.com/sol3/papers.cfm?abstract_id=789725. 
spread, yet often exclusively from high-frequency (thus, relatively small and recent) trade and quote datasets. ${ }^{7}$ Even daily quoted spread data are commonly available (on CRSP) only for the NASDAQ stock market. These constraints may severely limit the scope and time horizon of our study. The measure of Roll (1984) explicitly addresses this issue. Roll suggests that in an efficient market, trading costs induce negative serial dependence in prices, hence that the effective (i.e., within-quote) bid-ask spread can be estimated using return autocovariance.

In light of these considerations, we extract the firm-level adverse selection component of both the proportional quoted and Roll's (1984) effective bid-ask spreads over each fiscal year in the sample. We do so by employing the estimators of that component first introduced by George, Kaul, and Nimalendran (1991). Their basic argument is that uninformed trading activity (e.g., due to hedging motives) moves a stock's price (for liquidity reasons) but not the market expectation of its future payoffs, hence generating negatively autocorrelated stock returns; informational speculation, however, does induce a generally not instantaneous revision of those expectations, thus generating positively autocorrelated returns. George, Kaul, and Nimalendran (1991) show that filtering a stock's realized returns with a measure of its time-varying expected return allows for unbiased and efficient estimates of the adverse selection component of that stock's proportional spread, whether computed using actual quotes or daily returns. Following George, Kaul, and Nimalendran (1991), we estimate the fraction of proportional quoted and Roll's (1984) effective spread due to adverse selection for each stock $i$ over each fiscal year $\tau$ as $\mathrm{AD}_{i \tau}$ and $\mathrm{RAD}_{i \tau}$, respectively.

Market microstructure also exploits the different implications of hedging and speculation for the interaction of stock returns and trading volume to gauge the ensuing extent of adverse selection. In a recent study, Llorente et al. (2002) find that accounting for the intensity of trading volume can greatly improve the cross-sectional identification and measurement of the extent of hedging and speculation explaining stock price movements. Specifically, they show theoretically and confirm empirically that a correspondence exists between the cross-sectional variation in stocks' volume-return dynamics and the relative importance of information-driven trading in stocks' price fluctuations. Following their methodology, we estimate their explicit proxy for the relative importance of information asymmetry considerations among all stocks in our sample, $C 2_{i \tau}$. Within each fiscal year $\tau$, the lower (higher) is the estimated $C 2_{i \tau}$, the lower (higher) is firm $i$ 's degree of adverse selection.

Easley, Kiefer, and O'Hara (1996, 1997a, b); and Easley et al. (1996) develop a model in which uninformed market participants' perceived probability of the arrival of informed trades (PIN) can be inferred from the trading process itself, specifically from the frequency and magnitude of buy-sell imbalances. Intuitively, if no information event takes place, buy and sell orders arrive randomly.

\footnotetext{
7 See Huang and Stoll (1997); and Hasbrouck (2006) for a review.
} 
Buy and sell orders instead cluster during information days. Thus, the PIN can be estimated from the signed order flow and the greater the estimated $\mathrm{PIN}_{i \tau}$ (which we obtain from Easley, Hvidkjaer, and O'Hara 2004), the greater is the intensity of information asymmetry about firm $i$ 's value in fiscal year $\tau{ }^{8}$

All of the above-mentioned studies find that adverse selection is an important determinant of market liquidity, when the latter is proxied by either the bid-ask spread or trading volume. Yet, according to Hasbrouck (2005), there is "no single measure that captures all dimensions of liquidity." "For instance, Kyle (1985); and Amihud and Mendelson (1980) show that an alternative proxy for liquidity - the impact of order flow on market prices, known as lambdais increasing with adverse selection and inventory costs, respectively. Direct estimation and attribution of lambda requires transaction-level data (Hasbrouck 1991). The unavailability of such data over long periods of time motivates Amihud (2002) to develop a convenient proxy for lambda - the illiquidity ratio $\mathrm{ILL}_{i \tau}$, defined as the mean of the square root of the ratio of firm $i$ 's daily absolute stock return to the reported daily dollar volume (in millions) over all days in fiscal year $\tau$ with nonzero volume (Hasbrouck 2005). Amihud (2002) shows that ILL $_{i \tau}$ is strongly positively related to intraday estimates of lambda. Equivalently, when a firm's stock is liquid (either because of low adverse selection, inventory costs, or both), large trading volumes are accompanied by small price changes. The (Amivest) liquidity ratio $\mathrm{LR}_{i \tau}$ of Cooper, Groth, and Avera (1985); and Amihud, Mendelson, and Lauterbach (1997)—computed as minus the mean of the square root of the ratio of stock $i$ 's reported daily dollar volume (in millions) to its absolute stock return over all days in fiscal year $\tau$ with nonzero return - attempts to capture this notion. Therefore, ceteris paribus, the greater is the extent of adverse selection around firm $i$ in fiscal year $\tau$, the worse is that stock's liquidity, and the greater are $\operatorname{ILL}_{i \tau}$ and $\mathrm{LR}_{i \tau}$.

Lastly, Pastor and Stambaugh (2003) suggest that a stock's liquidity can be captured by the interaction between its returns and lagged order flow. Intuitively, since less liquid stocks may overshoot in response to order flow, the greater is a stock's estimated return reversal for a given dollar volume the lower is that stock's liquidity. Following Pastor and Stambaugh (2003), we compute the absolute magnitude of such reversal for each stock $i$ over each fiscal year $\tau$ and label it as $\mathrm{GAM}_{i \tau}$. Ceteris paribus, the greater is the extent of firm $i$ 's adverse selection during fiscal year $\tau$, the worse is that stock's liquidity, and the greater is $\mathrm{GAM}_{i \tau}$.

${ }^{8}$ Those estimates (at http://www.rhsmith.umd.edu/Finance/hvidkjaer/data.htm) are for all NYSE and AMEX stocks whose transaction data is available between 1983 and 2001 and whose fiscal year ends in December.

9 Amihud (2002, p. 35) adds, "It is doubtful that there is one single measure that captures all its aspects." Recently, Frieder and Martell (2005); and Lipson and Mortal (2006) have used effective bid-ask spreads to study the relation between liquidity per se and leverage for U.S. firms. 
Table 1

Summary statistics

\begin{tabular}{lcrrr} 
Variable & Obs. & Mean & Stdev & Median \\
\hline $\mathrm{RAD}_{i \tau}$ & 78429 & 0.35 & 0.27 & 0.31 \\
$\mathrm{C}_{i \tau}$ & 78849 & 0.01 & 0.15 & 0.02 \\
$\mathrm{AD}_{i \tau}$ & 29233 & 0.85 & 0.16 & 0.90 \\
$\mathrm{PIN}_{i \tau}$ & 12992 & 0.20 & 0.08 & 0.19 \\
$\mathrm{ILL}_{i \tau}$ & 84511 & 1.07 & 2.00 & 0.47 \\
$\mathrm{GAM}_{i \tau}$ & 78939 & 0.32 & 9.33 & 0.01 \\
$\mathrm{LR}_{i \tau}$ & 90338 & -7.77 & 18.01 & -2.08 \\
$\mathrm{ASY}_{i \tau}$ & 91471 & 0.00 & 1.80 & 0.39 \\
$\Delta \mathrm{ASY}_{i \tau}$ & 90965 & 0.00 & 2.08 & 0.81 \\
\hline
\end{tabular}

Summary statistics for the information asymmetry variables defined in the text over the sample period 1972-2002.

\subsection{Index construction}

The above methodologies generate seven measures that are conceptually positively related to the extent of adverse selection about firm $i$ in fiscal year $\tau$ : $\mathrm{AD}_{i \tau}, \mathrm{RAD}_{i \tau}, \mathrm{C}_{i \tau}, \mathrm{PIN}_{i \tau}, \mathrm{ILL}_{i \tau}, \mathrm{LR}_{i \tau}$, and $\mathrm{GAM}_{i \tau}$. Table 1 summarizes each of them. Table 2 reports means of fiscal year-level Spearman rank correlations among their cross-sectionally standardized levels (in Panel A, as $\mathrm{Z} \_\mathrm{AD}_{i \tau}$, $\mathrm{Z} \_R A D_{i \tau}, Z_{-} C 2_{i \tau}, Z_{\_} P I N_{i \tau}, Z_{-} I L L_{i \tau}, Z_{\_} L_{i \tau}$, and $Z_{-} G_{i \tau} M_{i \tau}$ ) and year-on-year firm-level changes (in Panel B, as $Z_{-} \Delta \mathrm{AD}_{i \tau}, \mathrm{Z}_{-} \Delta \mathrm{RAD}_{i \tau}, \mathrm{Z}_{-} \Delta \mathrm{C} 2_{i \tau}, \mathrm{Z}_{-} \Delta \mathrm{PIN}_{i \tau}$, $\mathrm{Z}_{-} \Delta \mathrm{ILL}_{i \tau}, \mathrm{Z}_{-} \Delta \mathrm{LR}_{i \tau}$, and $\mathrm{Z}_{-} \Delta \mathrm{GAM}_{i \tau}$ ). Each of the proxies' means in Table 1 is statistically significant and of the expected sign-i.e., all indicate that there is evidence of information asymmetry in the U.S. stock market between 1972 and 2002. ${ }^{10}$ Some of these proxies, in particular the latter three broader measures of liquidity, are likely to include an adverse selection component as well as noninformational components. Accordingly, Table 2 shows that the standardized proxies for firm-level information asymmetry are mostly positively correlated with each other, with the sole exception of $\mathrm{Z}_{-\mathrm{RAD}} \mathrm{D}_{i \tau}$ and $\mathrm{Z}_{-} \Delta \mathrm{RAD}_{i \tau}{ }^{11}$

This discussion motivates us to use principal components analysis to isolate the common component of the cross section of either the level of or annual change in our seven proxies for firm-level adverse selection in each fiscal year of our sample. Specifically, we estimate the first principal component of the correlation matrix of the available standardized proxies for the extent of firm-level adverse selection in each fiscal year $\tau, \mathrm{PCA}_{1 i \tau}$, as well as of the available year-on-year standardized changes in such extent, $\triangle \mathrm{PCA}_{1 i \tau}$. In both cases, the first principal component explains on average more than $50 \%$ of the corresponding cross-sectional sample variance. In addition, in most cases, only the first eigenvalue is significantly larger than one. We conclude that one factor captures much of the common variation among the seven proxies-i.e., the variation due to adverse selection. We then define a parsimonious index of either

${ }^{10}$ In addition, these means are consistent with estimates previously reported in the literature (e.g., Neal and Wheatley 1998; Hasbrouck 2005).

11 Neal and Wheatley (1998) attribute the latter to the restriction, overwhelmingly rejected by their analysis, that the fractions of the bid-ask spread due to order processing and adverse selection add to one. 
Table 2

Correlation matrices

$\mathrm{ASY}_{i \tau} \quad \mathrm{Z} \_\mathrm{RAD}_{i \tau} \quad \mathrm{Z}_{-} \mathrm{C} 2_{i \tau} \quad \mathrm{Z}_{-} \mathrm{AD}_{i \tau} \quad \mathrm{Z}_{-} \mathrm{PIN}_{i \tau} \quad \mathrm{ZZ}_{-} \mathrm{ILL}_{i \tau} \quad \mathrm{Z}_{-} \mathrm{GAM}_{i \tau} \quad \mathrm{Z} \_L R_{i \tau}$

Panel A: Standardized levels of information asymmetry

\begin{tabular}{|c|c|c|c|c|c|c|c|c|}
\hline $\mathrm{ASY}_{i \tau}$ & 1 & & & & & & & \\
\hline${\mathrm{Z} \_\mathrm{RAD}_{i \tau}}$ & $0.158^{\mathrm{a}}$ & 1 & & & & & & \\
\hline $\mathrm{Z}_{-} \mathrm{C} 2_{i \tau}$ & $0.273^{\mathrm{a}}$ & $-0.072^{\mathrm{a}}$ & 1 & & & & & \\
\hline $\mathrm{Z}_{-} \mathrm{AD}_{i \tau}$ & $0.141^{\mathrm{b}}$ & 0.037 & -0.022 & 1 & & & & \\
\hline $\mathrm{Z} \_P I N_{i \tau}$ & $0.513^{\mathrm{a}}$ & $-0.246^{\mathrm{a}}$ & $0.063^{\mathrm{a}}$ & -0.168 & 1 & & & \\
\hline $\mathrm{Z}_{\text {IILL }}{ }_{i \tau}$ & $0.385^{\mathrm{a}}$ & $-0.282^{\mathrm{a}}$ & $0.121^{\mathrm{a}}$ & $0.069^{c}$ & $0.675^{\mathrm{a}}$ & 1 & & \\
\hline $\mathrm{Z} \_G A M_{i \tau}$ & $0.308^{\mathrm{a}}$ & $-0.282^{\mathrm{a}}$ & $0.122^{\mathrm{a}}$ & $0.094^{\mathrm{b}}$ & $0.572^{\mathrm{a}}$ & $0.839^{\mathrm{a}}$ & 1 & \\
\hline${\mathrm{Z} \_L R_{i \tau}}$ & -0.065 & $-0.327^{\mathrm{a}}$ & $0.109^{\mathrm{a}}$ & $0.116^{\mathrm{a}}$ & $0.657^{\mathrm{a}}$ & $0.937^{\mathrm{a}}$ & $0.878^{\mathrm{a}}$ & 1 \\
\hline
\end{tabular}

Panel B: Standardized year-on-year changes in information asymmetry

$\triangle \mathrm{ASY}_{i \tau} \quad 1$

$\mathrm{Z}_{-} \triangle \mathrm{RAD}_{i \tau} \quad 0.244^{\mathrm{a}}$

$\mathrm{Z}_{-} \triangle \mathrm{C} 2_{i \tau} \quad 0.255^{\mathrm{a}} \quad-0.051^{\mathrm{a}}$

Z_ $\triangle \mathrm{AD}_{i \tau} \quad 0.251^{\mathrm{a}} \quad 0.132^{\mathrm{c}}$

$\mathrm{Z}_{-} \triangle \mathrm{PIN}_{i \tau} \quad 0.162^{\mathrm{a}}$

$\mathrm{Z}_{-} \triangle \mathrm{ILL}_{i \tau} \quad 0.238^{\mathrm{a}}$

$\mathrm{Z}_{-} \triangle \mathrm{GAM}_{i \tau} \quad 0.203^{\mathrm{a}}$

0.002

$-0.037^{\mathrm{a}}$

$-0.039^{\mathrm{a}}$

$-0.030^{\mathrm{a}}$

\begin{tabular}{cr}
1 & \\
$0.149^{\mathrm{c}}$ & \multicolumn{1}{c}{1} \\
0.009 & 0.175 \\
-0.001 & -0.032 \\
$0.039^{\mathrm{a}}$ & 0.100 \\
$0.038^{\mathrm{a}}$ & 0.035
\end{tabular}

1
$0.074^{\mathrm{a}}$
-0.003
0.014

1
$0.332^{\mathrm{a}}$

$0.014 \quad 0.500^{\mathrm{a}} \quad 0.228^{\mathrm{a}}$

$0.014 \quad 0.500^{\mathrm{a}} \quad 0.228^{\mathrm{a}}$

1

This table reports Spearman rank correlations for the standardized information asymmetry variables defined in the text over the sample period 1972-2002. a, b, c denote statistical significance at $1 \%, 5 \%$, and $10 \%$, respectively.

firm-level extent of or year-on-year change in adverse selection as $\mathrm{ASY}_{i \tau}=$ $\mathrm{PCA}_{1 i \tau}$ and $\Delta \mathrm{ASY}_{i \tau}=\Delta \mathrm{PCA}_{1 i \tau}$, respectively. This procedure ensures that we characterize firms' relative adverse selection in a year exclusively from data (and proxies) available in that year. Thus, by construction, the means of ASY A $_{i \tau}$ and $\triangle \mathrm{ASY}_{i \tau}$ are at zero in each fiscal year $\tau$ as well as over the entire sample (Table 1). ${ }^{12}$ Also by construction, the higher is $\operatorname{ASY}_{i \tau}\left(\Delta \mathrm{ASY}_{i \tau}\right)$, the higher is the (increase in the) severity of adverse selection problem for firm $i$ in fiscal year $\tau$. Finally, we employ $\operatorname{ASY}_{i \tau}\left(\Delta \mathrm{ASY}_{i \tau}\right)$ to rank each firm $i$ in the sample over each fiscal year $\tau$ into ten deciles from the lowest-lowest (change in) adverse selection risk - to the highest-highest (change in) adverse selection risk.

\subsection{Index properties}

Our index (and the ensuing rankings) has several appealing economic properties. First, each individual component almost always enters the index with the right (i.e., positive) sign. ${ }^{13}$ Second, the index loads primarily on the four direct proxies of adverse selection described in Section 2.1. For example, Table 2 shows that $\mathrm{ASY}_{i \tau}$ is most highly positively correlated with $\mathrm{ZLPIN}_{i \tau}(0.513$ in Panel A), while $\Delta \mathrm{ASY}_{i \tau}$ comoves the most with $\mathrm{Z}_{-} \Delta C 2_{i \tau}(0.255$ in Panel B).

12 However, neither the median of $\mathrm{ASY}_{i \tau}$ and $\Delta \mathrm{ASY}_{i \tau}$ is exactly zero nor the standard deviation is exactly one, since $\mathrm{ASY}_{i \tau}$ and $\triangle \mathrm{ASY}_{i \tau}$ are only the first principal component of their standardized constituents.

13 Equivalently, the elements of the first eigenvector used to compute $\mathrm{PCA}_{1 i \tau}$ (as well as those of the first eigenvector for $\left.\triangle \mathrm{PCA}_{1 i \tau}\right)$ are almost always positive in each fiscal year of the sample. 
In addition, the index loads on at least three of those proxies in each of the fiscal years of our sample. Yet, when the cross-sectional sample coverage by some of them is less than complete, the index can rely upon the adverse selection component of the three liquidity proxies. Third, $\mathrm{ASY}_{i \tau}$ and $\Delta \mathrm{ASY}_{i \tau}$ are similar but not identical (a statistically significant Spearman rank correlation of 0.660); so, neither is redundant when used to characterize the cross-sectional dispersion in (level of and fluctuations in) firm-level adverse selection over our sample. Fourth, the sets of firms comprising each of the $\mathrm{ASY}_{i \tau}$-based and $\triangle \mathrm{ASY}_{i \tau}$-based deciles display sensible characteristics. Table 3 reports means of various firm-level accounting variables (size, tangibility, $Q$ ratio, sales, and profitability) for firms in each decile of $\mathrm{ASY}_{i \tau}$ (Panel A) and $\Delta \mathrm{ASY}_{i \tau}$ (Panel B) as well as for the full sample. ${ }^{14}$ Table 4 reports the average percentage industry composition of each decile of $\mathrm{ASY}_{i \tau}$ (Panel A) and $\Delta \mathrm{ASY}_{i \tau}$ (Panel B), as well as of the full sample, according to the classification suggested by Kenneth French. ${ }^{15}$

According to Table 3, firms in low adverse selection deciles (low, 2, 3) are on average larger (in both assets and sales, in millions of year 2000 dollars) than their counterparts in high deciles $\left(8,9\right.$, high) when sorted by $\mathrm{ASY}_{i \tau}$, but not when sorted by $\triangle \mathrm{ASY}_{i \tau}$. Consistently, both the Spearman rank correlations and linear slope coefficients between average assets or sales and the corresponding adverse selection rankings ( $\rho^{\mathrm{SR}}$ and $b^{\mathrm{OLS}}$ in Table 3 ) are negative and significant for $\mathrm{ASY}_{i \tau}$-based sorts and negative and insignificant for $\Delta \mathrm{ASY}_{i \tau^{-}}$ based sorts. Thus, firm size seems to be more related to its (relative) level of information asymmetry than to its year-on-year fluctuations. Firms in lower adverse selection deciles are also neither more nor less (relatively) profitable and their assets are not less tangible — but their $Q$ ratios are higher-than for firms in high adverse selection deciles. Table 4 also suggests that the average industry composition of the sets of firms within each adverse selection decile is remarkably similar to the industry composition of the universe of firms in the sample. However, when ranked for their level of adverse selection, Manufacturing firms are more likely ( $\rho^{\mathrm{SR}}$ and $b^{\mathrm{OLS}}$ are positive and significant), and Shops firms less likely ( $\rho^{\mathrm{SR}}$ and $b^{\mathrm{OLS}}$ are negative and significant), to fall into high $\mathrm{ASY}_{i \tau}$ and $\Delta \mathrm{ASY}_{i \tau}$ deciles.

In short, Tables 3 and 4 indicate that our measures of firm-level adverse selection, $\mathrm{ASY}_{i \tau}$ and $\Delta \mathrm{ASY}_{i \tau}$, (1) do not systematically single out (so our ensuing inference is not driven by) any peculiar group of firms but (2) are still consistent with many (but not all) of the ex ante firm characteristics routinely employed by the corporate finance literature as proxies for firms' relative

\footnotetext{
14 Following standard practice (e.g., Frank and Goyal 2003), the balance sheet and cash flow statement variables as a percentage of assets are winsorized (by removing the most extreme $0.50 \%$ in either tail of the distribution) to purge outliers and the most extremely misreported data.

15 See http://mba.tuck.dartmouth.edu/pages/faculty/ken.french/data_library.html.
} 
Table 3

Accounting variables across adverse selection deciles

\begin{tabular}{|c|c|c|c|c|c|c|}
\hline Decile & Size & Tangibility & $Q$ ratio & Sales & Profitability & $\mathrm{IT}_{i \tau}$ \\
\hline \multicolumn{7}{|c|}{ Panel A: ASY $_{i \tau}$-based deciles } \\
\hline Low & $\$ 2,757$ & 0.29 & 4.31 & $\$ 2,320$ & -0.12 & 1.85 \\
\hline 2 & $\$ 2,470$ & 0.32 & 2.24 & $\$ 2,060$ & 0.07 & 1.22 \\
\hline 3 & $\$ 798$ & 0.31 & 1.90 & $\$ 678$ & 0.04 & 1.39 \\
\hline 4 & $\$ 1,108$ & 0.31 & 2.06 & $\$ 854$ & -0.01 & 1.44 \\
\hline 5 & $\$ 1,098$ & 0.31 & 2.38 & $\$ 844$ & 0.03 & 1.35 \\
\hline 6 & $\$ 988$ & 0.31 & 2.14 & $\$ 748$ & 0.00 & 1.27 \\
\hline 7 & $\$ 635$ & 0.30 & 2.05 & $\$ 516$ & -0.01 & 1.07 \\
\hline 8 & $\$ 493$ & 0.30 & 1.90 & $\$ 384$ & -0.04 & 1.59 \\
\hline 9 & $\$ 2,097$ & 0.33 & 1.89 & $\$ 1,638$ & 0.05 & 1.09 \\
\hline High & $\$ 374$ & 0.31 & 1.56 & $\$ 338$ & -0.06 & 1.72 \\
\hline Total & $\$ 1,288$ & 0.31 & 2.24 & $\$ 1,043$ & -0.01 & 1.39 \\
\hline$\rho^{\mathrm{SR}}$ & $-0.673^{b}$ & 0.164 & $-0.745^{\mathrm{a}}$ & $-0.673^{b}$ & -0.127 & -0.152 \\
\hline$b^{\text {OLS }}$ & $-\$ 164^{\mathrm{c}}$ & 0.00 & $-0.17^{\mathrm{b}}$ & $-\$ 141^{\mathrm{b}}$ & 0.00 & -0.01 \\
\hline Decile & Size & Tangibility & $Q$ ratio & Sales & Profitability & $\Delta \mathrm{IT}_{i \tau}$ \\
\hline \multicolumn{7}{|c|}{ Panel B: $\triangle \mathrm{ASY}_{i \tau}$-based deciles } \\
\hline Low & $\$ 793$ & 0.30 & 3.42 & $\$ 597$ & -0.11 & -0.59 \\
\hline 2 & $\$ 1,985$ & 0.28 & 2.99 & $\$ 1,600$ & -0.03 & -0.64 \\
\hline 3 & $\$ 1,725$ & 0.31 & 2.11 & $\$ 1,481$ & 0.04 & -0.71 \\
\hline 4 & $\$ 1,205$ & 0.31 & 2.14 & $\$ 1,135$ & 0.04 & -0.27 \\
\hline 5 & $\$ 1,055$ & 0.31 & 1.92 & $\$ 920$ & 0.01 & -0.22 \\
\hline 6 & $\$ 2,094$ & 0.32 & 1.80 & $\$ 1,685$ & 0.02 & -0.21 \\
\hline 7 & $\$ 1,831$ & 0.33 & 1.83 & $\$ 1,398$ & 0.05 & -0.10 \\
\hline 8 & $\$ 1,162$ & 0.31 & 2.02 & $\$ 857$ & 0.02 & -0.21 \\
\hline 9 & $\$ 968$ & 0.31 & 1.87 & $\$ 796$ & -0.01 & -0.04 \\
\hline High & $\$ 917$ & 0.31 & 1.74 & $\$ 723$ & 0.00 & -0.07 \\
\hline Total & $\$ 1,293$ & 0.31 & 2.24 & $\$ 1,048$ & -0.01 & -0.24 \\
\hline$\rho^{\mathrm{SR}}$ & -0.188 & 0.467 & $-0.842^{\mathrm{a}}$ & -0.273 & 0.164 & $0.903^{\mathrm{a}}$ \\
\hline$b^{\mathrm{OLS}}$ & $-\$ 35$ & $0.003^{\mathrm{c}}$ & $-0.15^{\mathrm{a}}$ & $-\$ 37$ & 0.01 & $0.07^{\mathrm{a}}$ \\
\hline
\end{tabular}

This table reports means of various firm characteristics for each adverse selection decile of firms over the sample period 1972-2002. $\rho^{\mathrm{SR}}$ and $b^{\mathrm{OLS}}$ are the Spearman rank correlation and linear regression coefficient, respectively, between the corresponding variable and either the $\mathrm{ASY}_{i \tau}$-based or the $\triangle \mathrm{ASY}{ }_{i \tau}$-based rankings; $\mathrm{a}, \mathrm{b}, \mathrm{c}$ denote their statistical significance at $1 \%, 5 \%$, and $10 \%$, respectively.

degree of information asymmetry. ${ }^{16}$ Yet, our index is able to capture the dynamic component of the degree of information asymmetry about a firm (e.g., around the time when its capital structure is modified), while the latter are by their nature essentially static. For sake of comparison, in unreported analysis (available at the reference in footnote 6) we sort firms by size into 10 deciles in each of the fiscal years of our sample. We then compute the percentage frequency by which firms move by zero, one, two, or three or more deciles of either size, $\mathrm{ASY}_{i \tau}$ or $\Delta \mathrm{ASY}_{i \tau}$ after one, three, or five years. We find that about $73 \%(82 \%)$ of the firms in our sample move to a different decile of $\mathrm{ASY}_{i \tau}$ $\left(\triangle \mathrm{ASY}_{i \tau}\right)$ the following year, and more of them do so after at least three years. However, when sorting firms by size, only $31 \%$ of them move to a new size

16 Clarke and Shastri (2001); Alford and Jones (2003); and Flannery, Kwan, and Nimalendran (2004) reach similar conclusions when analyzing many of the adverse selection measures entering $\mathrm{ASY}_{i \tau}$ and $\Delta \mathrm{ASY}_{i \tau}$. 
Table 4

Industry groupings across adverse selection deciles

Consumer Consumer Manufac-

Business

Decile nondurables durables turing Energy Chemicals Equipment Telecom Shops Healthcare Other

\begin{tabular}{lcccccccccc}
\hline Panel A: & ASY \\
L & -based deciles. & & & & & & & & \\
Low & $7 \%$ & $3 \%$ & $11 \%$ & $6 \%$ & $3 \%$ & $24 \%$ & $5 \%$ & $15 \%$ & $9 \%$ & $17 \%$ \\
2 & $9 \%$ & $4 \%$ & $14 \%$ & $4 \%$ & $3 \%$ & $19 \%$ & $4 \%$ & $18 \%$ & $9 \%$ & $16 \%$ \\
3 & $9 \%$ & $4 \%$ & $16 \%$ & $5 \%$ & $2 \%$ & $18 \%$ & $3 \%$ & $16 \%$ & $9 \%$ & $18 \%$ \\
4 & $8 \%$ & $3 \%$ & $15 \%$ & $6 \%$ & $2 \%$ & $20 \%$ & $3 \%$ & $15 \%$ & $10 \%$ & $18 \%$ \\
5 & $8 \%$ & $3 \%$ & $15 \%$ & $7 \%$ & $3 \%$ & $21 \%$ & $4 \%$ & $12 \%$ & $10 \%$ & $17 \%$ \\
6 & $8 \%$ & $3 \%$ & $15 \%$ & $8 \%$ & $3 \%$ & $22 \%$ & $3 \%$ & $12 \%$ & $10 \%$ & $17 \%$ \\
7 & $8 \%$ & $3 \%$ & $15 \%$ & $6 \%$ & $2 \%$ & $22 \%$ & $3 \%$ & $13 \%$ & $12 \%$ & $17 \%$ \\
8 & $8 \%$ & $4 \%$ & $15 \%$ & $6 \%$ & $2 \%$ & $22 \%$ & $3 \%$ & $13 \%$ & $11 \%$ & $17 \%$ \\
9 & $9 \%$ & $4 \%$ & $18 \%$ & $5 \%$ & $3 \%$ & $18 \%$ & $4 \%$ & $11 \%$ & $9 \%$ & $18 \%$ \\
High & $9 \%$ & $4 \%$ & $20 \%$ & $6 \%$ & $3 \%$ & $16 \%$ & $2 \%$ & $13 \%$ & $8 \%$ & $19 \%$ \\
\hline Total & $8 \%$ & $4 \%$ & $15 \%$ & $6 \%$ & $3 \%$ & $20 \%$ & $3 \%$ & $14 \%$ & $10 \%$ & $17 \%$ \\
$\rho^{\text {SR }}$ & 0.394 & 0.103 & $0.709^{\mathrm{b}}$ & 0.382 & 0.321 & -0.297 & $-0.612^{\mathrm{b}}$ & $-0.697^{\mathrm{b}}$ & 0.055 & 0.394 \\
$b^{\text {OLS }}$ & $0.1 \%$ & $0.0 \%$ & $0.6 \% \%^{\mathrm{a}}$ & $0.1 \%$ & $0.0 \%$ & $-0.3 \%$ & $-0.2 \%$ & $-0.5 \% \mathrm{~b}$ & $0.0 \%$ & $0.1 \%$ \\
\hline
\end{tabular}

Consumer Consumer Manufac-

Business

Decile nondurables durables turing Energy Chemicals Equipment Telecom Shops Healthcare Other

\begin{tabular}{lcccccccccc}
\hline Panel B: & \multicolumn{7}{c}{$\mathrm{ASY}_{i \tau}$-based deciles. } \\
Low & $7 \%$ & $3 \%$ & $13 \%$ & $6 \%$ & $2 \%$ & $23 \%$ & $4 \%$ & $13 \%$ & $10 \%$ & $18 \%$ \\
2 & $7 \%$ & $3 \%$ & $11 \%$ & $4 \%$ & $2 \%$ & $27 \%$ & $5 \%$ & $15 \%$ & $10 \%$ & $17 \%$ \\
3 & $8 \%$ & $4 \%$ & $15 \%$ & $5 \%$ & $3 \%$ & $20 \%$ & $3 \%$ & $16 \%$ & $10 \%$ & $17 \%$ \\
4 & $9 \%$ & $3 \%$ & $15 \%$ & $6 \%$ & $2 \%$ & $19 \%$ & $3 \%$ & $15 \%$ & $10 \%$ & $18 \%$ \\
5 & $8 \%$ & $4 \%$ & $16 \%$ & $6 \%$ & $3 \%$ & $19 \%$ & $3 \%$ & $15 \%$ & $10 \%$ & $17 \%$ \\
6 & $9 \%$ & $4 \%$ & $16 \%$ & $6 \%$ & $3 \%$ & $18 \%$ & $3 \%$ & $14 \%$ & $9 \%$ & $18 \%$ \\
7 & $9 \%$ & $4 \%$ & $20 \%$ & $8 \%$ & $4 \%$ & $15 \%$ & $3 \%$ & $11 \%$ & $9 \%$ & $17 \%$ \\
8 & $8 \%$ & $4 \%$ & $16 \%$ & $6 \%$ & $3 \%$ & $22 \%$ & $4 \%$ & $13 \%$ & $10 \%$ & $16 \%$ \\
9 & $9 \%$ & $4 \%$ & $17 \%$ & $6 \%$ & $3 \%$ & $20 \%$ & $3 \%$ & $12 \%$ & $10 \%$ & $18 \%$ \\
High & $8 \%$ & $4 \%$ & $17 \%$ & $5 \%$ & $3 \%$ & $21 \%$ & $3 \%$ & $13 \%$ & $10 \%$ & $18 \%$ \\
\hline Total & $8 \%$ & $4 \%$ & $15 \%$ & $6 \%$ & $3 \%$ & $20 \%$ & $3 \%$ & $14 \%$ & $10 \%$ & $17 \%$ \\
$\rho^{\text {SR }}$ & 0.503 & $0.552^{\mathrm{c}}$ & $0.891^{\mathrm{a}}$ & 0.127 & $0.576^{\mathrm{c}}$ & -0.309 & -0.527 & $-0.673^{\mathrm{b}}$ & -0.309 & -0.079 \\
$b^{\text {OLS }}$ & $0.1 \%{ }^{\mathrm{c}}$ & $0.04 \%{ }^{\mathrm{c}}$ & $0.6 \% \mathrm{~b}$ & $0.1 \%$ & $0.1 \%$ & $-0.5 \%$ & $-0.1 \%$ & $-0.3 \%$ & $0.0 \%$ & $-0.0 \%$ \\
\hline
\end{tabular}

This table reports the industry composition of each adverse selection decile of firms over the sample period 1972-2002. $\rho^{\mathrm{SR}}$ and $b^{\mathrm{OLS}}$ are the Spearman rank correlation and linear regression coefficient, respectively, between the corresponding variable and either the $\mathrm{ASY}_{i \tau}$-based or the $\triangle \mathrm{ASY}{ }_{i \tau}$-based rankings; $\mathrm{a}, \mathrm{b}, \mathrm{c}$ denote their statistical significance at $1 \%, 5 \%$, and $10 \%$, respectively.

decile after one year, and $40 \%$ of them still remain in the same decile even after five years. ${ }^{17}$

Alternatively, the information environment of a firm has been estimated by such more dynamic proxies as residual volatility of equity (Dierkens 1991), recent asset volatility (Halov and Heider 2004), R\&D activity (Aboody and Lev 2000), age (Berger and Udell 1995), magnitude of earnings surprises (Barclay and Smith 1995a, b), intensity of public announcements (Dierkens 1991), level of institutional ownership (Best, Hodges, and Lin 2004), analyst coverage (Chang, Dasgupta, and Hilary 2006), or dispersion of analysts' earnings forecasts (Krishnaswami and Subramaniam 1999; Gomes and Phillips 2005). Unfortunately, many of these measures have several, often conflictual

17 Sorting firms by their tangibility or $Q$ ratios generates similar results. 
or ad hoc interpretations. ${ }^{18}$ In addition, they have often been found to inadequately proxy for the degree of information asymmetry between insiders and other market participants. ${ }^{19}$ The majority of the components of our adverse selection index have instead been specifically devised by the microstructure literature, on the basis of theory, to capture the market's perceived intensity of information asymmetry about the payoffs of a firm's traded securities, i.e., ultimately about that firm's valuation. Overall, we believe these considerations make our adverse selection index apt to test whether information asymmetry problems affect firms' capital structure decisions. This is what we do next.

\section{Empirical Results}

\subsection{Debt issuance to cover financing deficits}

The pecking order theory of capital structure of Myers (1984); and Myers and Majluf (1984) predicts that firms prefer debt over equity because of information asymmetry between well-informed managers and less-informed investors. When investment needs exceed internal funds, they are met primarily with debt, while equity is used as a residual source of financing. To test for the pecking order theory, Shyam-Sunder and Myers (1999) suggest to regress net debt issuance $\left(\Delta D_{i \tau}\right)$ on the financing deficit $\left(\mathrm{DEF}_{i \tau}\right)$ as follows:

$$
\Delta D_{i \tau}=\alpha+\beta D F_{i \tau}+\varepsilon_{i \tau},
$$

where $\Delta D_{i \tau}$ is long-term debt issuance minus long-term debt reduction, while $\mathrm{DEF}_{i \tau}$ is given by the accounting cash flow identity

$$
\mathrm{DEF}_{i \tau}=\mathrm{DIV}_{i \tau}+\mathrm{CAPEX}_{i \tau}+\Delta \mathrm{WC}_{i \tau}-\mathrm{CF}_{i \tau}
$$

in which $\mathrm{DIV}_{i \tau}$ are dividend payments, $\mathrm{CAPEX}_{i \tau}$ are capital expenditures, $\Delta \mathrm{WC}_{i \tau}$ is the net change in working capital, and $\mathrm{CF}_{i \tau}$ is operating cash flow (after interest and taxes). All variables are scaled by total assets, as in Frank and Goyal (2003).

According to Shyam-Sunder and Myers (1999), the strict pecking order theory implies that the regression coefficient $\beta$ should be close to one, since firms would recur to equity only as a last resort. Myers (1984); and Myers and Majluf (1984) also describe a modified pecking order that recognizes the tradeoff between adverse selection costs and the costs of financial distress when too much debt is issued. Under the modified version of the theory, firms may issue equity in place of debt when faced with financing deficit to maintain both liquid assets and debt capacity for future investments. Therefore, the estimated

18 E.g., the evidence in Diether, Malloy, and Scherbina (2002); Pasquariello and Vega (2007); and Sadka and Scherbina (2007) suggests that dispersion in analysts' earnings forecasts (i.e., analyst disagreement) is a better proxy for differences in opinion about a security than for information asymmetry about its issuer.

19 For instance, Frankel and Li (2004); and Huddart and Ke (2007) find that institutional ownership, analyst following, financial statement informativeness, frequency of reporting of losses and R\&D, or market reaction to earnings announcements fail to explain insider trading activity and profits. 
slope coefficient in Equation (1) should still be positive but may be lower than one. Regardless of this debate, most existing tests on the pecking order do not examine a key assumption of that theory: the extent of information asymmetry problems plaguing firms' external funding. After all, Myers (2001) emphasizes that the pecking order theory is a conditional theory of firms' capital structure, one relating information differences to financing choices. As such, we should expect the pecking order theory to provide a relatively (more) accurate description of firms' financing behavior only when adverse selection costs associated with the issuance of information-sensitive securities are "large(r)." Accordingly, the modified pecking order theory predicts that, ceteris paribus, the regression coefficient $\beta$ should be greater for firms with higher information asymmetry. Several studies have examined this conditional relationship, e.g., with respect to information releases (Korajczyk, Lucas, and McDonald 1991), the aggregate volume of equity issuances (Bayless and Chaplinsky 1996), or the business cycle (Choe, Masulis, and Nanda 1993). In this study, we test for this relationship by measuring the severity of adverse selection costs with the adverse selection index described in Section 2.

We start by examining the slope coefficient $\beta$ in Equation (1) for firms sorted each fiscal year $\tau$ into deciles according to our information asymmetry index $\mathrm{ASY}_{i \tau}$. If the level of information asymmetry in any fiscal year $\tau$ is a key driver of firms' capital structure decisions in that year, we expect to find an increasing and monotonic ordering of the $\beta$ coefficient across the deciles. Further, we expect the difference in the $\beta$ coefficient between the highest and the lowest deciles to be positive and significant. For economy of space, we report here only the $\beta$ coefficients for the low (1) and high (10) $\mathrm{ASY}_{i \tau}$-based deciles of firms (estimated over the entire sample, Total), their corresponding robust (heteroskedasticity-consistent) $t$-statistics, and the $R^{2}$ of the regression in Table 5. We assess sign and significance of the relationship between our index and the extent of debt issuance to finance deficits by computing Spearman rank correlations $\left(\rho^{\mathrm{SR}}\right)$ and linear regression coefficients $\left(b^{\mathrm{OLS}}\right)$ between the estimated $\beta$ coefficients and their corresponding $\mathrm{ASY}_{i \tau}$-based rankings, as well as by estimating the coefficient for an interaction term of $\mathrm{DEF}_{i \tau}$ and $\mathrm{ASY}_{i \tau}(\gamma)$ in the following augmented version of Equation (1):

$$
\Delta D_{i \tau}=\alpha+\beta \mathrm{DEF}_{i \tau}+\gamma \mathrm{DEF}_{i \tau} \cdot \mathrm{ASY}_{i \tau}+\varepsilon_{i \tau}
$$

Those three slope statistics $\left(\rho^{\mathrm{SR}}, b^{\mathrm{OLS}}\right.$, and $\left.\gamma\right)$ are also reported in Table 5.

All estimates of $\beta$ are positive, smaller than one, and statistically significant at the $1 \%$ level. Hence, the pecking order theory, in its most restrictive interpretation, provides only a first-order approximation to the time-series variance in actual debt ratios, consistent with the extant literature (e.g., Shyam-Sunder and Myers 1999; Frank and Goyal 2003). More important, positive and statistically significant $\rho^{\mathrm{SR}}, b^{\mathrm{OLS}}$, and $\gamma$ statistics in Table 5 indicate that the $\beta$ coefficients are nearly monotonically increasing in the severity of firms' information asymmetry. For instance, the estimated $\gamma=0.021$ (with a $t$-statistic of 16.0) implies 
Table 5

Basic pecking order tests

\begin{tabular}{|c|c|c|c|c|c|c|c|c|c|c|c|c|c|}
\hline \multirow[b]{2}{*}{ Sample } & \multirow[b]{2}{*}{ Decile } & \multicolumn{6}{|c|}{ Panel A: $\mathrm{ASY}_{i \tau}$-based deciles } & \multicolumn{6}{|c|}{ Panel B: $\triangle \mathrm{ASY}_{i \tau}$-based deciles } \\
\hline & & Low & High & High-low & $\rho^{\mathrm{SR}}$ & $b^{\mathrm{OLS}}$ & $\gamma$ & Low & High & High-low & $\rho^{\mathrm{SR}}$ & $b^{\mathrm{OLS}}$ & $\gamma$ \\
\hline \multirow{3}{*}{ Total } & $\beta$ & $0.116^{\mathrm{a}}$ & $0.412^{\mathrm{a}}$ & $0.296^{\mathrm{a}}$ & $0.661^{\mathrm{b}}$ & $0.019^{\mathrm{a}}$ & $0.021^{\mathrm{a}}$ & $0.147^{\mathrm{a}}$ & $0.366^{\mathrm{a}}$ & $0.219^{\mathrm{a}}$ & $0.800^{\mathrm{a}}$ & $0.017^{\mathrm{a}}$ & $0.031^{\mathrm{a}}$ \\
\hline & $t(p)$ & 16.8 & 18.4 & 12.8 & $(0.04)$ & $(0.01)$ & 16.0 & 24.5 & 20.7 & 11.9 & $(0.01)$ & $(0.01)$ & 22.0 \\
\hline & $\mathrm{R}^{2}$ & $9 \%$ & $41 \%$ & & & & & $12 \%$ & $37 \%$ & & & & \\
\hline \multirow{3}{*}{1970 s } & $\beta$ & $0.515^{\mathrm{a}}$ & $0.921^{\mathrm{a}}$ & $0.406^{\mathrm{a}}$ & $0.952^{\mathrm{a}}$ & $0.039^{\mathrm{a}}$ & $0.077^{\mathrm{a}}$ & $0.580^{\mathrm{a}}$ & $0.916^{\mathrm{a}}$ & $0.335^{\mathrm{a}}$ & $0.830^{\mathrm{a}}$ & $0.036^{\mathrm{a}}$ & $0.072^{\mathrm{a}}$ \\
\hline & $\mathrm{t}(\mathrm{p})$ & 7.0 & 30.5 & 5.1 & $(0.00)$ & $(0.00)$ & 5.9 & 9.5 & 30.6 & 4.9 & $(0.00)$ & $(0.00)$ & 5.5 \\
\hline & $\mathrm{R}^{2}$ & $49 \%$ & $85 \%$ & & & & & $56 \%$ & $82 \%$ & & & & \\
\hline \multirow{3}{*}{$1980 \mathrm{~s}$} & $\beta$ & $0.245^{\mathrm{a}}$ & $0.609^{\mathrm{a}}$ & $0.367^{\mathrm{a}}$ & $0.964^{\mathrm{a}}$ & $0.043^{\mathrm{a}}$ & $0.022^{\mathrm{a}}$ & $0.255^{\mathrm{a}}$ & $0.637^{\mathrm{a}}$ & $0.382^{\mathrm{a}}$ & $1.000^{\mathrm{a}}$ & $0.044^{\mathrm{a}}$ & $0.038^{\mathrm{a}}$ \\
\hline & $\mathrm{t}(\mathrm{p})$ & 10.9 & 9.1 & 5.3 & $(0.00)$ & $(0.00)$ & 5.0 & 15.0 & 9.7 & 5.8 & n.a. & $(0.00)$ & 7.7 \\
\hline & $\mathrm{R}^{2}$ & $25 \%$ & $61 \%$ & & & & & $26 \%$ & $64 \%$ & & & & \\
\hline \multirow{3}{*}{$1990 s+$} & $\beta$ & $0.077^{\mathrm{a}}$ & $0.355^{\mathrm{a}}$ & $0.277^{\mathrm{a}}$ & 0.364 & $0.015^{\mathrm{c}}$ & $0.022^{\mathrm{a}}$ & $0.106^{\mathrm{a}}$ & $0.307^{\mathrm{a}}$ & $0.201^{\mathrm{a}}$ & $0.582^{\mathrm{c}}$ & $0.013^{\mathrm{b}}$ & $0.027^{\mathrm{a}}$ \\
\hline & $\mathrm{t}(\mathrm{p})$ & 11.3 & 15.4 & 11.7 & $(0.15)$ & $(0.07)$ & 14.0 & 17.6 & 17.3 & 10.8 & $(0.08)$ & $(0.04)$ & 19.9 \\
\hline & $\mathrm{R}^{2}$ & $5 \%$ & $36 \%$ & & & & & $8 \%$ & $32 \%$ & & & & \\
\hline
\end{tabular}

This table reports estimates for the coefficient $\beta$ in Equation (1) across deciles of firms sorted by either ASY or $\triangle \mathrm{ASY}_{i \tau}$, as well as the coefficient $\gamma$ for an additional interaction term of $\mathrm{DEF}_{i \tau}$ and either $\mathrm{ASY}_{i \tau}$ or $\triangle \mathrm{ASY}_{i \tau}$ $(\gamma)$ in Equation (1) (e.g., Equation (3)). a, b, c denote statistical significance at 1\%, 5\%, and 10\%, respectively, assessed with (heteroskedasticity) robust standard errors adjusted for firm-level clustering; the resulting $t$ statistics are reported below the corresponding estimate. $\rho^{\mathrm{SR}}$ and $b^{\mathrm{OLS}}$ are the Spearman rank correlation and linear regression coefficient, respectively, between the corresponding variable and either the $\mathrm{ASY}_{i \tau}$-based or the $\triangle \mathrm{ASY}_{i \tau}$-based rankings; their $p$-values are in parentheses.

that on average, for every dollar of financing deficit to cover in a fiscal year, firms whose adverse selection index is a unit greater than the mean that year issue two more cents of debt. Further, the difference between the $\beta$ coefficients at the two extreme deciles of firms (the high-low $\beta$ column in Table 5) is large (0.296) and strongly statistically significant (a $t$-statistic of 12.8): on average, for every dollar of financing deficit to cover, firms in the highest ASY $_{i \tau}$ decile issue 30 cents of debt more than firms in the lowest ASY $_{i \tau}$ decile. These results clearly indicate that cross-sectional variation in adverse selection across firms is related to the cross section of their capital structure decisions in a fashion consistent with the pecking order theory: the higher the level of a firm's information asymmetry, the more of its financing needs are satisfied by the issuance of debt.

Perhaps, cross-sectional variation in the time-series behavior of firms' debt ratios is related-in a fashion consistent with the pecking order theory-not only to the level of, but also to the change in the relative severity of information asymmetry about them over time: the greater the increase in a firm's adverse selection costs over the previous fiscal year, the greater the portion of its financing deficit that firm may fund through debt in the current fiscal year. Hence, as a further (and possibly more stringent) test of the basic tenets of the pecking order theory, we estimate the debt-deficit regressions of Equation (1) across deciles of U.S. firms sorted on the basis of the relative change in their adverse selection risk from the previous fiscal year $\left(\Delta \mathrm{ASY}_{i \tau}\right){ }^{20}$ Table 5

20 We are indebted to Stewart Myers for recommending this line of action to us. 
reports the resulting $\beta$ estimates for the overall sample. Remarkably, the ensuing inference mirrors closely the one based on $\mathrm{ASY}_{i \tau}$ : firms experiencing the greater change in adverse selection risk with respect to the previous fiscal year follow the pecking order more closely (display larger $\beta s$ ) in the current year. ${ }^{21}$

Lastly, we examine the cross-sectional performance of the pecking order theory (i.e., of $\beta$ of Equation (1)) for $\mathrm{ASY}_{i \tau^{-}}$and $\Delta \mathrm{ASY}_{i \tau}$-based deciles of firms in three distinct time periods of our sample: 1972-1979, 1980-1989, and 1990-2002. The resulting estimates, also reported in Table 5, suggest that our previous inference may not apply uniformly to all three subperiods. The estimated $\beta$ s are always positive and lower than one, and the differences between the $\beta$ coefficients for the highest and lowest information asymmetry deciles of firms are large and statistically significant in each of these subperiods. However, the magnitude of those differences (yet not their significance) declines in the 1990s. The magnitude of the slope statistics $\rho^{\mathrm{SR}}, b^{\mathrm{OLS}}$, and $\gamma$ displays a similar trend, although all but one of them ( $\rho^{\mathrm{SR}}$ for $\mathrm{ASY}_{i \tau}$-based sorts) remain statistically significant in the 1990s. This evidence is consistent with a trend highlighted by Frank and Goyal (2003); and Fama and French (2005). Fama and French find that U.S. firms have been issuing more equity more frequently over the past three decades, through mergers, private placements, convertible debt, warrants, direct purchase plans, rights issues, and employee options, grants, and benefit plans. For instance, they report that, between 1973 and 1982, on average $67 \%$ of the firms in their sample issued some equity each year; this proportion rises to $74 \%$ between 1983 and 1992, and to $86 \%$ between 1993 and 2002. Accordingly, Frank and Goyal (2003) show that a large and increasing portion of external financing took the form of equity during the 1990s. We revisit this issue in our discussion of further tests of the pecking order theory next.

Overall, this evidence indicates that in the presence of financing needs, U.S. firms display greater preference for debt, both statistically and economically, when plagued with greater extent of and change in adverse selection costs - consistent with the main assumption of the pecking order theory, albeit seemingly less so in the 1990s.

\subsection{Conventional leverage regressions}

The regression model of Equation (1) was first introduced by Shyam-Sunder and Myers (1999) as a test of a strict pecking order theory. Chirinko and Singha (2000) question that interpretation by showing that equity issues can induce a negative bias in the test. The inference we presented so far (Table 5) is based on differences in those regression coefficients across information asymmetry deciles, rather than on their magnitude. Thus, it is potentially less susceptible to this bias, yet only if such bias is roughly constant across deciles. Further, a modified interpretation of the theory requires only for the pecking order to be

${ }^{21}$ Similar inference ensues from sorting firms into either quintiles or terciles based on $\mathrm{ASY}_{i \tau}$ or $\Delta \mathrm{ASY}_{i \tau}$. 
an "excellent first-order descriptor of corporate financing behavior" (ShyamSunder and Myers 1999, p. 242), albeit not the only one. However, Chirinko and Singha (2000) also point out that if firms follow a policy of using debt and equity in fixed proportions, in violation of the pecking order, the estimated $\beta$ coefficient may simply capture that ratio. Thus, it is of interest to examine the empirical relevance of the main assumption of the pecking order theory within alternative, more conventional empirical leverage specifications. Indeed, according to Frank and Goyal (2003, p. 223), ignoring these specifications may amount to a "significant omission," yet their adoption may pose a "tough test for the pecking order theory."

Rajan and Zingales (1995) survey the extant literature on factors driving leverage and distill its key implications into a simple model relating the cross section of firm leverage to such conventional firm characteristics as size, tangibility, profitability, and market-to-book assets ratio. We augment their model to include the extent of firm-level adverse selection $\mathrm{ASY}_{i \tau}$ in the following firm fixed effects panel regression:

$$
\begin{aligned}
\text { Leverage }_{i \tau}= & a+u_{i}+b_{1} \mathrm{ASY}_{i \tau}+b_{2} \text { Tangibility }_{i \tau}+b_{3} Q \text { ratio }_{i \tau} \\
& +b_{4} \operatorname{Logsales}_{i \tau}+b_{5} \text { Profitability }_{i \tau}+\varepsilon_{i \tau},
\end{aligned}
$$

where Logsales $_{i \tau}$ is the natural log of net sales (another proxy for firm size) and $u_{i}$ are firm fixed effects. The literature has produced several definitions of firm leverage. Rajan and Zingales (1995) discuss the merits and weaknesses of each. In this study, we employ the broadest and most widely adopted measure of firm $i$ 's leverage in fiscal year $\tau$, Leverage ${ }_{i \tau}$ : the ratio of total debt to market value of assets, $\mathrm{DMA}_{i \tau}$, as in Shyam-Sunder and Myers (1999). The inference that follows is unaffected by defining leverage as the ratio of total debt to either the book value of asset or market capitalization, as in Frank and Goyal (2003), or by estimating Equation (4) without firm fixed effects. If information asymmetry is an important determinant of firms' debt issuance decisions, whose cumulative effect is leverage, we expect the coefficient on $\operatorname{ASY}_{i \tau}\left(b_{1}\right)$ to be positive and significant. Table 6 presents the results.

Both sign and significance of the coefficients for the conventional variables are in line with the literature. Therefore, the inclusion of our adverse selection proxy does not supersede their effects on leverage, as a strict interpretation of the pecking order theory would imply. However, the coefficient on $\mathrm{ASY}_{i \tau}$ in the firm fixed effects regression of Equation (4) is positive, large, and strongly significant in column (1) of Table 6. This estimate indicates that after accounting for various firm characteristics, the level of market leverage of firms whose adverse selection problems are the most severe (i.e., in the highest ASY $_{i \tau}$ decile) is on average 172 basis points greater than for firms whose adverse selection problems are the least severe (i.e., in the lowest $\mathrm{ASY}_{i \tau}$ decile). This difference amounts to $7.5 \%$ of the mean firm-level market leverage over our sample period. Since the dependent variable in Equation (4) is bounded between zero and one, we also estimate a Tobit regression. Its results, in column (2), 
Table 6

Conventional leverage regressions

\begin{tabular}{|c|c|c|c|c|c|c|c|c|c|c|c|c|}
\hline \multirow[b]{2}{*}{ Equation (4) } & OLS & Tobit & OLS & OLS & OLS & OLS & \multirow[b]{2}{*}{ Equation (5) } & OLS & OLS & OLS & OLS & OLS \\
\hline & (1) & (2) & (3) & (4) & (5) & (6) & & (7) & (8) & (9) & (10) & (11) \\
\hline \multirow[t]{2}{*}{$\operatorname{ASY}_{i \tau}$} & $0.404^{\mathrm{a}}$ & $0.283^{\mathrm{a}}$ & & $0.374^{\mathrm{a}}$ & $0.483^{\mathrm{a}}$ & $0.714^{\mathrm{a}}$ & $\Delta \mathrm{ASY}_{i \tau}$ & $0.298^{\mathrm{a}}$ & & $0.267^{\mathrm{a}}$ & $0.190^{\mathrm{a}}$ & $0.252^{\mathrm{a}}$ \\
\hline & 8.5 & 4.3 & & 7.5 & 9.1 & 11.6 & & 5.7 & & 4.9 & 3.4 & 4.8 \\
\hline \multirow[t]{2}{*}{$\operatorname{ASY}_{i \tau, 70 s}$} & & & $0.301^{\mathrm{b}}$ & & & & $\Delta \mathrm{ASY}_{i \tau, 70 \mathrm{~s}}$ & & 0.022 & & & \\
\hline & & & 2.1 & & & & & & 0.2 & & & \\
\hline \multirow[t]{2}{*}{$\operatorname{ASY}_{i \tau, 80 s}$} & & & $0.436^{\mathrm{a}}$ & & & & $\triangle \mathrm{ASY}_{i \tau, 80 s}$ & & $0.331^{\mathrm{a}}$ & & & \\
\hline & & & 5.6 & & & & & & 3.5 & & & \\
\hline \multirow[t]{2}{*}{$\mathrm{ASY}_{i \tau, 90 s+}$} & & & $0.402^{\mathrm{a}}$ & & & & $\triangle \mathrm{ASY}_{i \tau, 90 s+}$ & & $0.321^{\mathrm{a}}$ & & & \\
\hline & & & 6.9 & & & & & & 5.1 & & & \\
\hline \multirow[t]{2}{*}{ Turnover } & & & & -0.398 & & & $\Delta$ Turnover & & & $-0.365^{\mathrm{a}}$ & & \\
\hline & & & & -1.3 & & & & & & -3.1 & & \\
\hline \multirow[t]{2}{*}{ Volatility } & & & & $0.061^{\mathrm{a}}$ & & & $\Delta$ Volatility & & & $0.029^{\mathrm{a}}$ & & \\
\hline & & & & 15.0 & & & & & & 9.5 & & \\
\hline \multirow[t]{2}{*}{$\mathrm{IT}_{i \tau}$} & & & & & -0.007 & & $\Delta \mathrm{IT}_{i \tau}$ & & & & 0.004 & \\
\hline & & & & & -0.7 & & & & & & 0.7 & \\
\hline$Q \mathrm{xASY}_{i \tau}$ & & & & & & $\begin{array}{c}-0.116^{\mathrm{a}} \\
-5.4\end{array}$ & $\Delta Q \mathrm{x} \Delta \mathrm{ASY}_{i \tau}$ & & & & & $\begin{array}{c}-0.170^{\mathrm{a}} \\
-3.6\end{array}$ \\
\hline \multirow[t]{2}{*}{ Tangibility } & $0.198^{\mathrm{a}}$ & $0.184^{\mathrm{a}}$ & $0.198^{\mathrm{a}}$ & $0.193^{\mathrm{a}}$ & $0.184^{\mathrm{a}}$ & $0.197^{\mathrm{a}}$ & $\Delta$ Tangibility & $0.129^{\mathrm{a}}$ & $0.129^{\mathrm{a}}$ & $0.125^{\mathrm{a}}$ & $0.119^{\mathrm{a}}$ & $0.128^{\mathrm{a}}$ \\
\hline & 18.5 & 40.5 & 18.5 & 18.1 & 16.7 & 18.4 & & 12.9 & 12.9 & 12.4 & 11.6 & 12.9 \\
\hline \multirow[t]{2}{*}{$Q$ ratio } & $-0.009^{\mathrm{a}}$ & $-0.019^{\mathrm{a}}$ & $-0.009^{\mathrm{a}}$ & $-0.008^{\mathrm{a}}$ & $-0.008^{\mathrm{a}}$ & $-0.011^{\mathrm{a}}$ & $\triangle Q$ ratio & $-0.005^{\mathrm{a}}$ & $-0.005^{\mathrm{a}}$ & $-0.005^{\mathrm{a}}$ & $-0.005^{\mathrm{a}}$ & $-0.005^{\mathrm{a}}$ \\
\hline & -4.1 & -4.8 & -4.1 & -3.9 & -4.0 & -4.3 & & -5.1 & 5.1 & -5.0 & -5.0 & -4.8 \\
\hline \multirow[t]{2}{*}{ Logsales } & $0.023^{\mathrm{a}}$ & $0.001^{\mathrm{a}}$ & $0.023^{\mathrm{a}}$ & $0.026^{\mathrm{a}}$ & $0.025^{\mathrm{a}}$ & $0.023^{\mathrm{a}}$ & $\triangle$ Logsales & -0.002 & -0.002 & 0.000 & -0.002 & -0.001 \\
\hline & 15.4 & 3.4 & 15.4 & 17.0 & 15.8 & 14.9 & & -1.0 & 1.0 & 0.0 & -1.1 & -0.7 \\
\hline \multirow[t]{4}{*}{ Profitability } & -0.012 & -0.006 & -0.012 & -0.009 & -0.012 & -0.013 & $\triangle$ Profitability & -0.007 & -0.007 & -0.007 & -0.007 & -0.007 \\
\hline & -1.5 & -1.3 & -1.5 & -1.3 & -1.5 & -1.5 & & -1.5 & 1.5 & -1.3 & -1.5 & -1.6 \\
\hline & & & & & & & Leverage $_{i \tau-1}$ & $-0.487^{\mathrm{a}}$ & $-0.487^{\mathrm{a}}$ & $-0.492^{\mathrm{a}}$ & $-0.489^{\mathrm{a}}$ & $-0.485^{\mathrm{a}}$ \\
\hline & & & & & & & & -74.9 & -74.9 & -75.0 & -70.9 & -72.7 \\
\hline Obs. & 77265 & 77265 & 77265 & 76680 & 71804 & 77265 & Obs. & 61926 & 61926 & 61369 & 57118 & 61926 \\
\hline Overall $R^{2}$ & $7.38 \%$ & n.a. & $7.38 \%$ & $9.24 \%$ & $7.56 \%$ & $8.04 \%$ & Overall $R^{2}$ & $7.14 \%$ & $7.13 \%$ & $7.59 \%$ & $6.74 \%$ & $7.31 \%$ \\
\hline
\end{tabular}

This table reports estimates for the $b_{n}$ coefficients from firm fixed effects and Tobit panel regressions of Equation (4) for Leverage $e_{i \tau}=\mathrm{DMA}_{i \tau}$ and from fixed-effects regressions of Equation (5) for $\triangle$ Leverage $_{i \tau}=\triangle \mathrm{DMA}_{i \tau}$. We do not report the coefficient for the intercept. a, b, c denote statistical significance at $1 \%, 5 \%$, and $10 \%$, respectively, assessed with (heteroskedasticity) robust standard errors adjusted for firm-level clustering; the resulting $t$-statistics are reported below each estimate. Estimates for coefficients related to $\mathrm{ASY}_{i \tau}, \triangle \mathrm{ASY}_{i \tau}, \mathrm{IT}_{i \tau}$, and $\triangle \mathrm{IT}_{i \tau}$ are multiplied by 100 .

are very similar. Hence, the extent of firm-level adverse selection helps explain the cross-sectional variation in firms' capital structures-in accordance with the main assumption of the pecking order theory-even after controlling for conventional leverage factors in the literature.

Frank and Goyal (2003) argue that a stronger test of the main implication of the strict pecking order theory-namely, $\beta=1$ in Equation (1) - for the cross section of firms' financing decisions can be constructed by running Equation (4) in first differences. Accordingly, if adverse selection is an important determinant of debt issuance decisions - the main assumption of the pecking order theorywe expect greater $\mathrm{ASY}_{i \tau}$ to lead to higher leverage in the cross section of U.S. firms. Thus, we expect a positive and significant coefficient on $\Delta \mathrm{ASY}_{i \tau}$ in the following firm fixed effects panel regression:

$$
\begin{aligned}
\Delta \text { Leverage }_{i \tau}= & a+u_{i}+b_{1} \Delta \mathrm{ASY}_{i \tau}+b_{2} \Delta \text { Tangibility }_{i \tau}+b_{3} \Delta Q \text { ratio }_{i \tau} \\
& +b_{4} \Delta \text { Logsales }_{i \tau}+b_{5} \Delta \text { Profitability }_{i \tau}+b_{6} \text { Leverage }_{i \tau-1}+\varepsilon_{i \tau},
\end{aligned}
$$


where all variables are fiscal year-on-year changes of the level variables in Equation (4). Equation (5) also includes lagged leverage to account for the evidence of mean reversion in leverage in the literature (e.g., Taggart 1977; Marsh 1982). These estimates are also reported in Table 6 (column (7)). Sign and significance of the coefficients for the year-on-year changes in the conventional variables are again in line with the literature (e.g., Frank and Goyal 2003). Further, the coefficient for lagged leverage is large, negative, and significant, suggesting some mean reversion in leverage among U.S. firms. Nonetheless, even after accounting for these considerations, the coefficient on $\Delta \mathrm{ASY}_{i \tau}$ in the firm fixed effects regression of Equation (5) is positive and strongly significant. Hence, changes in the extent of firm-level adverse selection help explain the cross-sectional variation in changes in firms' capital structures.

Lastly, we examine whether the extent and significance of the relationship between firm-level adverse selection and the cross section of firm leverage in the United States reported in Table $6\left(b_{1}>0\right.$ in columns (1), (2), and (7)) change over time, as suggested by Table 5. To that purpose, we replace ASY $i \tau$ and $\triangle \mathrm{ASY}_{i \tau}$ in Equations (4) and (5) with their interaction with dummies for three portions of the sample period: 1972-1979 $\left(\mathrm{ASY}_{i \tau, 70 \mathrm{~s}}\right.$ and $\Delta \mathrm{ASY}_{i \tau, 70 \mathrm{~s}}$ ), 1980-1989 ASY $_{i \tau, 80 \mathrm{~s}}$ and $\left.\Delta \mathrm{ASY}_{i \tau, 80 \mathrm{~s}}\right)$, and 1990-2002 (ASY $\mathrm{A}_{i \tau, 90 \mathrm{~s}+}$ and $\left.\Delta \mathrm{ASY}_{i \tau, 90 \mathrm{~s}+}\right)$. The resulting coefficients' estimates, in columns (3) and (8) of Table 6 , are always positive and strongly statistically significant in the 1980s and 1990 s but less so in the 1970 s, especially for $\Delta \mathrm{ASY}_{i \tau}$. Accordingly, unreported $t$-tests fail to reject the null hypothesis that those estimates do not differ across the three subperiods, with the sole exception of $\Delta \mathrm{ASY}_{i \tau, 70 \mathrm{~s}}$.

Overall, these results provide strong confirmation that asymmetric information considerations are important-though by no means the sole factor or uniformly so-in explaining capital structure decisions of U.S. firms over the past three decades, consistent with the main assumption of the pecking order theory.

\subsection{Alternative index construction}

A crucial aspect of the procedure for the construction of our information asymmetry index is the extraction of the adverse selection component of several market measures of stock liquidity. It is nonetheless possible that, despite our efforts, our index may still be affected by such noninformational drivers of stock liquidity as dealers' risk aversion or inventory.

We investigate the importance of these concerns as follows. First, we sort all firms into terciles based on either annual standard deviation of stock returns or share turnover, from the lowest (1) to the highest (3). Ceteris paribus, we expect risk-averse dealers to provide less liquidity to more volatile stocks (e.g., Stoll 1978). Higher turnover gives dealers greater flexibility to offset their inventory, thus leading to greater stock liquidity (e.g., Jegadeesh and Subrahmanyam 1993). We then estimate Equation (1) across adverse selection deciles of firms within each of these subsets. To save space, we report (in Table 7) only the 
Table 7

Two-way sorts for pecking order tests

Panel A: ASY $_{i \tau}$-based deciles

High-low $\beta \quad t$-stat $\quad \rho^{\text {SR }} \quad b^{\text {OLS }}$
Panel B: $\triangle \mathrm{ASY}_{i \tau}$-based deciles

\begin{tabular}{|c|c|c|c|c|c|c|c|c|c|c|c|}
\hline & & & & & & & & & & \\
\hline & & High-low $\beta$ & $t$-stat & $\rho^{\mathrm{SR}}$ & $b^{\mathrm{OLS}}$ & $\gamma$ & High-low $\beta$ & $t$-stat & $\rho^{\mathrm{SR}}$ & $b^{\mathrm{OLS}}$ & $\gamma$ \\
\hline \multirow{3}{*}{ Volatility } & Low & $0.458^{\mathrm{a}}$ & 10.6 & $0.903^{\mathrm{a}}$ & $0.037^{\mathrm{b}}$ & $0.067^{\mathrm{a}}$ & $0.350^{\mathrm{a}}$ & 8.3 & $0.952^{\mathrm{a}}$ & $0.030^{\mathrm{a}}$ & $0.051^{\mathrm{a}}$ \\
\hline & Med & $0.257^{\mathrm{a}}$ & 4.6 & $0.867^{\mathrm{a}}$ & $0.026^{\mathrm{a}}$ & $0.038^{\mathrm{a}}$ & $0.199^{\mathrm{a}}$ & 6.1 & $0.891^{\mathrm{a}}$ & $0.017^{\mathrm{a}}$ & $0.029^{\mathrm{a}}$ \\
\hline & High & $0.313^{\mathrm{a}}$ & 12.8 & $0.818^{\mathrm{a}}$ & $0.021^{\mathrm{a}}$ & $0.028^{\mathrm{a}}$ & $0.234^{\mathrm{a}}$ & 10.7 & $0.782^{\mathrm{a}}$ & $0.017^{\mathrm{a}}$ & $0.026^{\mathrm{a}}$ \\
\hline \multirow{3}{*}{ Turnover } & Low & $0.278^{\mathrm{a}}$ & 7.8 & 0.455 & $0.016^{\mathrm{c}}$ & $0.022^{\mathrm{a}}$ & $0.211^{\mathrm{a}}$ & 5.6 & $0.745^{\mathrm{b}}$ & $0.019^{\mathrm{b}}$ & $0.044^{\mathrm{a}}$ \\
\hline & Med & $0.290^{\mathrm{a}}$ & 8.2 & $0.685^{\mathrm{b}}$ & $0.018^{\mathrm{b}}$ & $0.043^{\mathrm{a}}$ & $0.224^{\mathrm{a}}$ & 7.2 & $0.564^{\mathrm{c}}$ & $0.016^{\mathrm{b}}$ & $0.029^{\mathrm{a}}$ \\
\hline & High & $0.217^{\mathrm{a}}$ & 5.0 & $0.697^{b}$ & $0.016^{\mathrm{b}}$ & $0.030^{\mathrm{a}}$ & $0.194^{\mathrm{a}}$ & 7.4 & $0.903^{\mathrm{a}}$ & $0.016^{\mathrm{a}}$ & $0.026^{\mathrm{a}}$ \\
\hline \multirow{3}{*}{ Size } & Low & $0.190^{\mathrm{a}}$ & 8.0 & $0.770^{\mathrm{a}}$ & $0.013^{\mathrm{a}}$ & $0.011^{\mathrm{a}}$ & $0.155^{\mathrm{a}}$ & 7.6 & 0.539 & $0.010^{c}$ & $0.019^{\mathrm{a}}$ \\
\hline & Med & $0.626^{\mathrm{a}}$ & 20.9 & $0.758^{\mathrm{a}}$ & $0.045^{\mathrm{a}}$ & $0.048^{\mathrm{a}}$ & $0.384^{\mathrm{a}}$ & 12.0 & $0.745^{\mathrm{b}}$ & $0.032^{\mathrm{a}}$ & $0.051^{\mathrm{a}}$ \\
\hline & High & $0.360^{\mathrm{a}}$ & 10.3 & $0.745^{\mathrm{b}}$ & $0.025^{\mathrm{b}}$ & $0.041^{\mathrm{a}}$ & $0.226^{\mathrm{a}}$ & 6.9 & $0.709^{\mathrm{b}}$ & $0.020^{\mathrm{a}}$ & $0.032^{\mathrm{a}}$ \\
\hline \multirow{3}{*}{ Tangibility } & Low & $0.273^{\mathrm{a}}$ & 8.2 & $0.758^{\mathrm{b}}$ & $0.018^{\mathrm{a}}$ & $0.018^{\mathrm{a}}$ & $0.236^{\mathrm{a}}$ & 8.5 & $0.600^{\mathrm{c}}$ & $0.016^{\mathrm{b}}$ & $0.026^{\mathrm{a}}$ \\
\hline & Med & $0.221^{\mathrm{a}}$ & 5.5 & 0.418 & 0.012 & $0.021^{\mathrm{a}}$ & $0.165^{\mathrm{a}}$ & 5.5 & 0.539 & $0.014^{\mathrm{b}}$ & $0.026^{\mathrm{a}}$ \\
\hline & High & $0.288^{\mathrm{a}}$ & 6.7 & $0.600^{c}$ & $0.018^{\mathrm{b}}$ & $0.026^{\mathrm{a}}$ & $0.152^{\mathrm{a}}$ & 3.9 & $0.782^{\mathrm{a}}$ & $0.018^{\mathrm{a}}$ & $0.029^{\mathrm{a}}$ \\
\hline \multirow{3}{*}{$Q$ ratio } & Low & $0.569^{\mathrm{a}}$ & 14.2 & $0.552^{\mathrm{c}}$ & $0.038^{\mathrm{b}}$ & $0.067^{\mathrm{a}}$ & $0.449^{\mathrm{a}}$ & 10.6 & $0.636^{\mathrm{b}}$ & $0.040^{\mathrm{b}}$ & $0.075^{\mathrm{a}}$ \\
\hline & Med & $0.411^{\mathrm{a}}$ & 9.4 & 0.382 & 0.020 & $0.049^{\mathrm{a}}$ & $0.263^{\mathrm{a}}$ & 5.0 & 0.527 & $0.020^{\mathrm{c}}$ & $0.045^{\mathrm{a}}$ \\
\hline & High & $0.175^{\mathrm{a}}$ & 6.7 & $0.636^{\mathrm{b}}$ & $0.011^{\mathrm{b}}$ & $0.016^{\mathrm{a}}$ & $0.142^{\mathrm{a}}$ & 7.0 & $0.636^{\mathrm{b}}$ & $0.010^{\mathrm{b}}$ & $0.018^{\mathrm{a}}$ \\
\hline \multirow{4}{*}{$\mathrm{IT}_{i \tau}$} & Zero & $0.225^{\mathrm{a}}$ & 7.5 & 0.527 & $0.013^{b}$ & $0.018^{\mathrm{a}}$ & $0.205^{\mathrm{a}}$ & 8.7 & $0.818^{\mathrm{a}}$ & $0.019^{\mathrm{a}}$ & $0.028^{\mathrm{a}}$ \\
\hline & Low & $0.409^{\mathrm{a}}$ & 6.0 & 0.406 & $0.021^{\mathrm{c}}$ & $0.036^{\mathrm{a}}$ & $0.169^{\mathrm{a}}$ & 4.4 & $0.648^{b}$ & $0.014^{\mathrm{c}}$ & $0.027^{\mathrm{a}}$ \\
\hline & Med & $0.422^{\mathrm{a}}$ & 6.6 & $0.600^{c}$ & $0.033^{\mathrm{a}}$ & $0.040^{\mathrm{a}}$ & $0.373^{\mathrm{a}}$ & 7.3 & 0.527 & $0.022^{\mathrm{b}}$ & $0.035^{\mathrm{a}}$ \\
\hline & High & $0.407^{\mathrm{a}}$ & 8.2 & $0.830^{\mathrm{a}}$ & $0.038^{\mathrm{a}}$ & $0.033^{\mathrm{a}}$ & $0.363^{\mathrm{a}}$ & 7.6 & $0.782^{\mathrm{a}}$ & $0.029^{\mathrm{a}}$ & $0.039^{\mathrm{a}}$ \\
\hline
\end{tabular}

This table reports estimates for the difference between $\beta$ coefficients in Equation (1) for the highest and lowest information asymmetry deciles of firms based on either $\mathrm{ASY}_{i \tau}$ or $\triangle \mathrm{ASY}_{i \tau}$, as well as the coefficient $\gamma$ for an additional interaction term of $\mathrm{DEF}_{i \tau}$ and either $\mathrm{ASY}_{i \tau}$ or $\triangle \mathrm{ASY}_{i \tau}(\gamma)$ in Equation (1) (e.g., Equation (3)) across subsets of firms sorted by various firm characteristics into terciles. a, b, c denote statistical significance at $1 \%, 5 \%$, and $10 \%$, respectively, assessed with (heteroskedasticity) robust standard errors adjusted for firm-level clustering; the resulting $t$-statistics are to the right of the corresponding estimate. $\rho^{\mathrm{SR}}$ and $b^{\mathrm{OLS}}$ are the Spearman rank correlation and linear regression coefficient, respectively, between the corresponding variable and either the $\mathrm{ASY}_{i \tau}$-based or the $\triangle \mathrm{ASY}_{i \tau}$-based rankings.

corresponding differences in the $\beta$ coefficients between the highest and the lowest deciles of information asymmetry - as well as our tests for sign and significance of the relationship between $\beta$ coefficients and information asymmetry $\left(\rho^{\mathrm{SR}}, b^{\mathrm{OLS}}\right.$, and $\left.\gamma\right)$-for sorts based on either the level of (ASY ${ }_{i \tau}$, Panel A) or change in $\left(\Delta \mathrm{ASY}_{i \tau}\right.$, Panel $\left.\mathrm{B}\right)$ information asymmetry. Complete estimation details are available on request. We find that the debt-deficit coefficients $\beta$ are generally increasing in adverse selection deciles — and their high-low ASY $_{i \tau}$-based and $\triangle \mathrm{ASY}_{i \tau}$-based differences both economically and statistically significant -in all of the volatility and turnover-based terciles. ${ }^{22}$ For instance, column $b^{\text {OLS }}$ in Table 7 indicates that on average, for every dollar of financing deficit to cover, firms in each turnover tercile issue nearly two additional cents of debt more than firms in the same turnover tercile but in the next lower $\mathrm{ASY}_{i \tau}$-based or $\triangle \mathrm{ASY}_{i \tau}$-based decile. Accordingly, sign and significance of the coefficients for $\mathrm{ASY}_{i \tau}$ and $\Delta \mathrm{ASY}_{i \tau}$ in the fixed-effect regressions of Equations (4) and (5) are unaffected by the inclusion of both turnover and stock return volatility

22 Similar inference stems from computing stock return volatility as the annual sum of daily square returns. 
(or their first differences) as additional explanatory variables to conventional leverage factors (including firm size and tangibility, further discussed in Section 3.4), in columns (4) and (9) of Table 6.

Second, we construct a new index based exclusively on either the level of $\left(\mathrm{ASY}_{i \tau}^{*}\right)$ or the change in $\left(\Delta \mathrm{ASY}_{i \tau}^{*}\right)$ the four most direct measures of adverse selection from the market microstructure literature in our sample - the adverse selection portion of the quoted and effective bid-ask spread $\left(A D_{i \tau}\right.$ and $\mathrm{RAD}_{i \tau}$, respectively), the interaction between trading volume and asset returns $\left(C 2_{i \tau}\right)$, and the probability of informed trading $\left(\mathrm{PIN}_{i \tau}\right)$ - at the cost of smaller sample coverage. We then estimate Equation (1) within each of the resulting $\mathrm{ASY}_{i \tau^{-}}^{*}$ based or $\Delta \mathrm{ASY}_{i \tau}^{*}$-based deciles of firms and report the differences between the $\beta$ coefficients at the two extreme deciles and the corresponding slope statistics in Panels A and B of Table A1 of the Appendix, respectively. We also estimate the conventional leverage regressions of Section 3.2 (columns (1), (2), (4)-(7), and (9)-(11) in Table 6) using this new index-i.e., by replacing $\mathrm{ASY}_{i \tau}$ and $\Delta \mathrm{ASY}_{i \tau}$ with $\mathrm{ASY}_{i \tau}^{*}$ and $\Delta \mathrm{ASY}_{i \tau}^{*}$ in Equations (4) and (5), respectively. The resulting estimated coefficients of interest $\left(b_{1}\right)$ are reported in Table A2 of the Appendix. We find our previous inference from Tables 5 and 6 to be virtually unaffected. For instance, (1) for every dollar of financing deficit to cover, firms in the highest ASY ${ }_{i \tau}^{*}$ decile issue 24.3 cents of debt more than firms in the lowest $\mathrm{ASY}_{i \tau}^{*}$ decile (the high-low $\beta$ column in Panel A of Table A1), a difference similar to that stemming from the original $\mathrm{ASY}_{i \tau}$-based sorts (in Panel A of Table 5); (2) all the corresponding slope statistics indicate that the estimated $\beta$ coefficients are nearly monotonically increasing in either $\operatorname{ASY}_{i \tau}^{*}(\gamma=\$ 0.043$ in Equation (3)) or $\mathrm{ASY}_{i \tau}^{*}$-based rankings $\left(\rho^{\mathrm{SR}}=0.903\right.$ and $\left.b^{\mathrm{OLS}}=\$ 0.021\right)$; and (3) the coefficient on $\mathrm{ASY}_{i \tau}^{*}\left(b_{1}\right)$ in Table A2 is positive and strongly statistically significant (at the 1\% level) in all the specifications of Equation (4), as previously found for $\mathrm{ASY}_{i \tau}$ in Table 6. This is not surprising since the Spearman rank correlation between the broader ASY $i \tau$ index and the first principal component of only $\mathrm{Z} \_\mathrm{RAD}_{i \tau}, \mathrm{Z}_{-} \mathrm{C} 2_{i \tau}, \mathrm{Z}_{-} A D_{i \tau}$, and $\mathrm{Z}_{-} \mathrm{PIN} \mathrm{N}_{i \tau}$ is high (0.772).

Lastly, we repeat the analysis of Tables 5 and 6 using each of the four most direct market microstructure measures of adverse selection in our sample separately. For example, in each fiscal year of our sample, we sort the available firms based on either $Z_{-} C 2_{i \tau}$ or $Z_{-} \Delta C 2_{i \tau}$ and estimate Equation (1) within each $\mathrm{Z}_{-} \mathrm{C} 2_{i \tau}$-based or $\mathrm{Z}_{-} \Delta \mathrm{C} 2_{i \tau}$-based decile of firms. Table A1 reports the differences between the $\beta$ coefficients at the two extreme deciles of either Z_RAD ${ }_{i \tau}$,

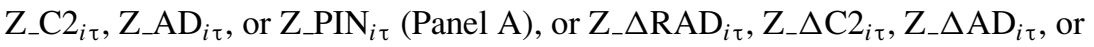
$\mathrm{Z}_{-} \Delta \mathrm{PIN} \mathrm{N}_{i \tau}$ (Panel B) and the corresponding slope statistics; Table A2 reports estimates of the adverse selection coefficient $b_{1}$ in Equations (4) and (5) after replacing $\mathrm{ASY}_{i \tau}$ and $\Delta \mathrm{ASY}_{i \tau}$ with the standardized level of or change in either $\mathrm{RAD}_{i \tau}, \mathrm{C} 2_{i \tau}, \mathrm{AD}_{i \tau}$, or $\mathrm{PIN}_{i \tau}$. This evidence suggests that the inference based on these measures, despite their more limited sample coverage, is generally (although not uniformly) similar (both qualitatively and quantitatively) 
to that based on the broad adverse selection index in Sections 3.1 and 3.2. In particular, in most of the measure-specific tests in Table A1, both the estimated high-low $\beta$ coefficient differences and the slope statistics $\rho^{\mathrm{SR}}, b^{\mathrm{OLS}}$, and $\gamma$ are either economically and statistically similar or qualitatively similar (i.e., of the same sign but not statistically significant) to those reported in Table $5 .^{23}$ Further, Table A2 indicates that in all but two of the new sets of measure-specific regressions, the relevant estimated coefficients $b_{1}$ are positive and, in most cases, strongly statistically significant as well (even after controlling for firm size, tangibility, turnover, and stock return volatility, in columns (4) and (9)).

Overall, we conclude that (1) our measure of information asymmetry has significant incremental explanatory power for the cross section of the relationship between debt issuances and financing deficits, over and above such firm characteristics as stock return volatility and stock liquidity; (2) the cross-sectional variation in either the level of or changes in firms' leverage is related to either the extent of or changes in firm-level adverse selection; and (3) this inference is generally robust to the procedure for the construction of our adverse selection index and to the choice of index components.

\subsection{Alternative measures of information asymmetry}

As previously discussed, the corporate finance literature has employed several alternative measures of the information environment of a firm. In light of computational ease, firm size is probably the most common conditioning variable in capital structure studies. It is often argued that the pecking order theory should perform well for small firms since their information costs are likely to be the largest (e.g., Frank and Goyal 2003, p. 237). Extant empirical evidence strongly rejects this hypothesis by showing that the coefficient $\beta$ in Equation (1) is increasing (rather than decreasing) in firm size (e.g., Frank and Goyal 2003). Yet, this evidence cannot be directly attributed to the extent of firms' adverse selection, for firm size is likely to capture other firm characteristics as well (e.g., their reputation in debt markets or the extent their assets are diversified). Tangibility of a firm's assets is another common, easy-to-calculate proxy for that firm's information asymmetry problems. According to Harris and Raviv (1991), adverse selection should be more severe, and the pecking order theory more relevant, for firms whose assets are less tangible-i.e., more difficult to value. However, Frank and Goyal (2003) find that firms with more tangible assets tend to issue more debt, a result they attribute to these firms' intrinsically greater debt capacity.

23 The sole exception is the level of PIN, Z_PIN $i t$, for which the high-low $\beta$ coefficient difference and corresponding slope statistics are negative and statistically significant. Sample coverage for PIN is much more limited than for the other direct adverse selection proxies (see Table 1). Nonetheless, inference from either debt-deficit regressions across firm deciles based on changes in PIN (Z_APIN $i t$ in Panel B of Table A1) or conventional leverage regressions (Table A2) is consistent with inference from $\mathrm{ASY}_{i t}$ and $\Delta \mathrm{ASY}_{i t}$. For more on the relationship between PIN and firms' leverage, see Agarwal and O'Hara (2006). 
We confirm these results in our sample. In unreported analysis, we sort firms in each fiscal year into deciles of either size or tangibility from the lowest to the highest and estimate the slope coefficient $\beta$ in Equation (1) for each decile. The resulting differences between the $\beta$ coefficients at the two extreme size and tangibility deciles are positive (0.568 and 0.393$)$ and strongly statistically significant (with $t$-statistics of 34.6 and 19.7). More important, those estimated $\beta$ coefficients are strictly increasing (e.g., $\rho^{\mathrm{SR}}=1$ ) in both size and tangibility rankings. Consistently, the coefficients for sales and tangibility in the conventional leverage regressions of Equation (4) in Table 6 are also positive and strongly statistically significant (at the $1 \%$ level). Yet, this evidence cannot be interpreted as rejecting the pecking order theory since these tests are joint tests of whether the sorting variable (size or tangibility) is an adequate proxy for firm-level adverse selection as well. The evidence in Tables 5 and 6 overcomes this difficulty, for our measure of information asymmetry $\left(\mathrm{ASY}_{i \tau}\right.$ and $\Delta \mathrm{ASY}_{i \tau}$ ) is based exclusively upon market microstructure proxies, grounded in theory, extracting the perceived intensity of firm-level adverse selection from observed market prices and trades.

We nonetheless intend to ascertain whether firm size and tangibility supersede our information asymmetry index when testing for the pecking order theory. To that purpose, we sort all firms into terciles of either size or tangibility in each of the fiscal years of the sample and estimate Equation (1) across either $\mathrm{ASY}_{i \tau}$ or $\Delta \mathrm{ASY}_{i \tau}$ deciles within each size and tangibility tercile. We report the resulting differences between $\beta$ coefficients at the two extreme adverse selection deciles of firms and slope statistics in Table 7. The latter almost uniformly indicate that the estimated $\beta$ 's are nearly monotonically increasing in the extent of (and change in) firms' adverse selection within each size and tangibility tercile. Accordingly, the estimated high-low $\mathrm{ASY}_{i \tau}$-based (Panel A) and $\Delta \mathrm{ASY}_{i \tau}$-based (Panel B) $\beta$ differences are both positive and statistically and economically significant for either small or large firms, or firms with few or many tangible assets. For example, for every dollar of financing deficit to cover, firms with highly tangible assets in the highest $\mathrm{ASY}_{i \tau}$ decile issue 29 cents of debt more than firms with highly tangible assets but in the lowest ASY $_{i \tau}$ decile (with a $t$-statistic of 6.7). These results are consistent with those reported in Table 6, where the coefficients for either $\mathrm{ASY}_{i \tau}$ or $\Delta \mathrm{ASY}_{i \tau}$ in conventional leverage regressions are also positive and statistically and economically significant despite the inclusion of net sales and tangibility among the regressors. This evidence suggests that cross-sectional variation in adverse selection is large enough-even across firms of similar observable characteristics as size and tangibility - to relate to the cross section of firms' capital structure decisions in a statistically and economically significant fashion and consistent with the pecking order theory.

The pecking order theory crucially depends on the information asymmetry between firm managers (insiders) and markets being the friction leading to a hierarchy of financing choices to minimize adverse selection costs of security 
issuance. Our market microstructure measures (and the resulting index $\mathrm{ASY}_{i \tau}$ or $\left.\Delta \mathrm{ASY}_{i \tau}\right)$ are designed to capture the degree of information asymmetry among market participants, which may arise from information asymmetry between insiders and outsiders of the firm. Yet, as discussed earlier, these measures may also proxy for asymmetry between a broader category of agents-informed traders - and uninformed traders. Hence, our inference might be biased insofar as these informed traders are not (related to) the insiders (managers) of the pecking order theory. To assess the relevance of these considerations, we construct an alternative measure of adverse selection based on the intensity of insider trading activity for each firm and in each fiscal year of the sample. For that purpose, we collect insider trading data from the Securities and Exchange Commission (SEC) Ownership Reporting System (ORS) data file for as many firms in our sample as possible. The SEC-ORS database contains all transactions by insiders that are subject to disclosure according to Section 16(a) of the Securities and Exchange Act of 1934, and is available to us only between 1978 and 2000. Following Lakonishok and Lee (2001), we classify management as insiders and identify their purchases and sales. We use this database to compute the extent of insider trading activity for each firm $i$ in each fiscal year $\tau$ as one hundred times the percentage ratio between the total volume of insider purchases and sales and the corresponding overall trading volume, $\mathrm{IT}_{i \tau}$. Intuitively, the greater this measure, the more intense is the trading activity of firm $i$ 's insiders in year $\tau$; hence the greater may have been their information advantage with respect to outsiders. Summary statistics for $\mathrm{IT}_{i \tau}$ (not reported here) indicate that over the available sample period insider trading is uncommon (a zero median), on average positive (1.39\% of a firm's annual trading volume), but only weakly positively correlated to our information asymmetry index and most firm characteristics.

We employ this alternative proxy $\mathrm{IT}_{i \tau}$ as follows. First, in unreported analysis, we sort firms in each fiscal year either into deciles of positive $\mathrm{IT}_{i \tau}$ from the lowest to the highest or into a no-insider trading set $\left(\mathrm{IT}_{i \tau}=0\right)$ and estimate the slope coefficient $\beta$ in Equation (1) for each grouping. We find that (1) even in the absence of insider trading, firms fund $26 \%$ of their financing deficits with debt ( $\beta=0.262$ with a $t$-statistic of 39.8$)$; (2) the difference between the $\beta$ coefficients at the two extreme deciles of positive IT $_{i \tau}$ firms is weakly positive and small (0.053); and (3) none of the slope statistics is statistically significant. Second, we sort all firms either into terciles of positive $\mathrm{IT}_{i \tau}$ or into the no-insider trading set $\left(\mathrm{IT}_{i \tau}=0\right)$ in each of the fiscal years of the sample and then estimate Equation (1) across either $\mathrm{ASY}_{i \tau}$ or $\Delta \mathrm{ASY}_{i \tau}$ deciles within each $\mathrm{IT}_{i \tau}$ grouping. The resulting differences between $\beta$ coefficients at the two extreme adverse selection deciles of firms - as well as the corresponding slope statistics (with the exception of $\rho^{\mathrm{SR}}$ ) —are always positive, large, and strongly statistically significant in Table 7-consistent with the pecking order theory (as in Table 5) — not only in each of the three positive-IT ${ }_{i \tau}$ terciles of firms but also within firms with no disclosed insider trading. For instance, Panel A of 
Table A2 indicates that on average, firms whose $\mathrm{IT}_{i \tau}=0$ and in the highest $\mathrm{ASY}_{i \tau}$ decile issue 23 cents of debt more than firms whose $\mathrm{IT}_{i \tau}=0$ but in the lowest $\mathrm{ASY}_{i \tau}$ decile. Third, we include $\mathrm{IT}_{i \tau}$ as an additional explanatory variable in Equation (4), and its first difference $\left(\Delta \mathrm{IT}_{i \tau}\right)$ as an additional explanatory variable in Equation (5). We report estimates for these amended conventional leverage regressions in columns (5) and (10) of Table 6. The coefficients on both level of and change in insider trading are statistically insignificant-consistent with the evidence in Table 7-while the inference on both $\mathrm{ASY}_{i \tau}$ and $\Delta \mathrm{ASY}_{i \tau}$ is unchanged. ${ }^{24}$

We conclude that our market microstructure-based index of firm-level adverse selection appears to capture a facet of information asymmetry not subsumed by size, tangibility, or intensity of insider trading and, as such, has incremental, economically significant explanatory power for the cross section of firms' financing decisions over those firm attributes.

\subsection{Tobin's $Q$ and information asymmetry}

In its original formulation, the pecking order theory of Myers and Majluf (1984) suggests that firms with fewer growth opportunities (i.e., with greater assets in place) are more likely to issue debt to fund their financing deficits when plagued by adverse selection problems. Intuitively, investors deem those firms' managers are more likely to overvalue their assets in place; hence, those firms' equity issuances are more likely to be undervalued. We test for this argument in two ways. First, for each fiscal year $\tau$, we sort the firms in our sample into three terciles based on their $Q$ ratios in that year. Consistent with the literature, we interpret low (high) $Q$ firms as firms with greater assets in place (growth opportunities). We then estimate Equation (1) for each of the resulting $30 Q-$ $\mathrm{ASY}_{i \tau}$ (and $Q-\Delta \mathrm{ASY}_{i \tau}$ ) subsets of firms and report the ensuing high-low $\beta$ coefficient differences and corresponding slope statistics in Panel A (Panel B) of Table 7.

Table 5 shows that over the full sample the $\beta$ coefficients are nearly monotonically increasing across information asymmetry rankings, and the differences between $\beta$ coefficients at the extreme rankings are positive, large, and strongly statistically significant. If the above argument is correct, we should expect those differences to be larger, and the monotonic relation to be more pronounced, among firms with lower $Q$ ratios. According to Table 7, those firms do appear to be the most sensitive to adverse selection considerations when funding their deficits. For instance, Panel A shows that for every dollar of financing deficit to cover, firms within the lowest $Q$ ratio tercile but in the highest adverse selection decile issue on average nearly 60 cents of debt more than firms in the same $Q$ ratio tercile but the lowest adverse selection decile; that difference statistically

${ }^{24}$ Similar inference is drawn by computing IT $_{i \tau}$ only with insider purchases (Lakonishok and Lee 2001). 
significantly declines (with $t$-statistics of 2.7 and 8.2) to about 40 cents and 20 cents for firms within the medium and high $Q$ ratio terciles. In addition, the extent to which firms whose $\mathrm{ASY}_{i \tau}$ is a unit greater than the mean in a fiscal year issue more debt for every dollar of financing deficit to cover in that year (column $\gamma$ ) is statistically significantly different (at the $1 \%$ level, in unreported tests) and strictly decreasing across $Q$ terciles (from nearly seven cents to less than two cents). ${ }^{25}$ Sorting firms on changes in information asymmetry $\left(\Delta \mathrm{ASY}_{i \tau}\right.$ in Panel B) leads to a similar inference.

Equations (4) and (5) allow us to perform a more challenging test of the above argument. Specifically, we test whether-conditional on both the extent of firms' growth opportunities and the conventional set of explanatory factors for leverage-our proxies for either the level of or the change in adverse selection better explain the cross section of either the level of or the change in firm leverage. To that purpose, we augment Equation (4) with an interaction term of $Q$ ratio $_{i \tau}$ and $\mathrm{ASY}_{i \tau}$ and Equation (5) with an interaction term of $\Delta Q$ ratio $_{i \tau}$ and $\Delta \mathrm{ASY}_{i \tau}$. We report the results of this estimation in columns (6) and (11) of Table 6 . If the effect of adverse selection on firm leverage is more pronounced for firms that have relatively more assets in place (lower $Q$ ), the estimated coefficients for both interaction terms should be negative and significant. The evidence in Table 6 strongly supports this prediction. In accordance with Table 7, it indicates that U.S. firms' debt issuance decisions are more sensitive to information asymmetry considerations when assets in place represent a greater portion of their value (low $Q$ ratio), as postulated by the pecking order theory.

\subsection{Further robustness tests}

The basic test of the pecking order theory of Equation (1) examines the relationship between a firm's debt issuances and its financing deficits. According to Shyam-Sunder and Myers (1999, p. 224), Equation (1) "is not an accounting identity"- - since the definition of financing deficits $\left(\mathrm{DEF}_{i \tau}\right.$ of Equation (2)) does not include equity issues or buybacks - but is meant to capture the extent to which the main implication of the pecking order theory, in its strict interpretation, holds in the data: any aggregate nonzero deficit, regardless of its source, should be funded with debt. Thus, Shyam-Sunder and Myers (1999) aggregate the accounting data in Equation (2) into $\mathrm{DEF}_{i \tau}$. However, the ensuing regression of Equation (1) does not control for the possibility that, ceteris paribus, some firms may not need any funds (and so may not issue any debt) because they are experiencing little or no growth in their business activity. The presence

25 Similarly, column $b^{\text {OLS }}$ in Table 7 indicates that on average, low $Q$ firms fund through debt nearly four cents of financing deficit more than firms in the same $Q$ tercile but in the next lower $\mathrm{ASY}_{i \tau}$-based decile; the estimated $b^{\text {OLS }}$ coefficient is statistically significantly lower (at the $10 \%$ level, in unreported tests) by almost three cents for the high $Q$ tercile, and statistically insignificant for the medium $Q$ tercile of firms. 
of such firms in the sample may bias our analysis toward rejection of a less strict interpretation of the pecking order theory.

We address this issue by amending Equation (1) to include each of the three main sources of firms' financing deficits-dividends, investments, and cash flow-separately (along the lines of Frank and Goyal 2003) as follows:

$$
\Delta D_{i \tau}=\alpha+\beta_{1} \mathrm{DIV}_{i \tau}+\beta_{2} \mathrm{INV}_{i \tau}+\beta_{3} \mathrm{CF}_{i \tau}+\varepsilon_{i \tau},
$$

where $\mathrm{INV}_{i \tau}=\mathrm{CAPEX}_{i \tau}+\Delta \mathrm{WC}_{i \tau}$ captures a firm's demand for funds due to its real investments. Equation (6) allows us to establish which of the explicitly disaggregated components of $\mathrm{DEF}_{i \tau}$ is driving the cross-sectional relationship between funding needs, debt issuance, and adverse selection found in Table 5. A strict interpretation of the pecking order theory requires that $\beta_{1}=\beta_{2}=$ $-\beta_{3}=1$. The basic assumption of the modified version of the theory implies that the absolute value of each of these coefficients be increasing in the severity of adverse selection problems plaguing the issuing firms. In particular, ceteris paribus, a firm's financing needs that are more directly related to the growth of its business (such as $\mathrm{INV}_{i \tau}$, its real investments) should be more likely to be funded with debt (i.e., $\beta_{2}$ is greater) the greater is the information asymmetry about that firm's business.

We report the resulting differences between the estimated $\beta_{n}$ coefficients at the two extreme adverse selection deciles of firms and the corresponding slope statistics $\left(\rho^{\mathrm{SR}}, b^{\mathrm{OLS}}\right.$, and $\left.\gamma\right)$ in Table A1 of the Appendix. Those statistics indicate that estimates for $\beta_{1}, \beta_{2}$, and $\left|\beta_{3}\right|$ are nearly monotonically increasing across deciles of severity of information asymmetry, consistent with the modified version of the pecking order theory. In particular, so is the coefficient for funding needs related to a firm's investment activity $\left(\operatorname{INV}_{i \tau}\right)$-i.e., more directly related to its growth. For example, the difference between estimated $\beta_{2}$ in Equation (6) for the highest and lowest adverse selection deciles of firms is always large (0.307 for $\mathrm{ASY}_{i \tau}$-based sorts, in Panel A, and 0.243 for $\Delta \mathrm{ASY}_{i \tau}$-based sorts, in Panel B) and statistically significant (with $t$-statistics of 12.6 and 12.8). We conclude that information asymmetry is an important determinant of a firm's capital structure choice in response to each of its funding needs, including when those needs are driven by that firm's real investments.

\section{Conclusion}

We use a novel information asymmetry index - based on either the level or change in adverse selection measures developed by the market microstructure literature - to reexamine several popular tests of the pecking order theory. Our index relies exclusively on measures of the market's assessment of adverse 
selection risk, rather than on ex ante firm characteristics, and displays sensible economic properties.

We find that firm-level asymmetric information considerations are important-albeit not the sole-determinants of the cross section of level and change in leverage of U.S. firms over the past three decades. These findings are robust to the procedure for the construction of our measure of adverse selection index, to the choice of its components, as well as to controlling for conventional leverage factors (size, tangibility, $Q$ ratio, profitability), the sources of firms' financing needs, and such firm attributes as stock return volatility, stock turnover, and intensity of insider trading.

Our evidence does not corroborate a strict interpretation of the pecking order theory. Nonetheless, it indicates that a modified pecking order theory finds the greatest support, both statistically and economically, when its basic assumption-severe adverse selection-holds the most in the data. Consistent with Myers (2001), we believe the latter constitutes the theory's most appropriate benchmark.

\section{Appendix}

Table A1

Further pecking order tests

\begin{tabular}{|c|c|c|c|c|c|c|c|c|c|c|c|}
\hline & \multicolumn{5}{|c|}{ Panel A: Level-based deciles } & & \multicolumn{5}{|c|}{ Panel B: Change-based deciles } \\
\hline & High-low $\beta$ & $t$-stat & $\rho^{\mathrm{SR}}$ & $b^{\mathrm{OLS}}$ & $\gamma$ & & High-low & $t$-stat & $\rho^{\mathrm{SR}}$ & $b^{\text {OLS }}$ & $\gamma$ \\
\hline $\mathrm{ASY}_{i \tau}^{*}$ & $0.243^{\mathrm{a}}$ & 11.5 & $0.903^{\mathrm{a}}$ & $0.021^{\mathrm{a}}$ & $0.043^{\mathrm{a}}$ & $\triangle \mathrm{ASY}_{i \tau}^{*}$ & $0.200^{\mathrm{a}}$ & 10.2 & $0.709^{\mathrm{b}}$ & $0.016^{\mathrm{a}}$ & $0.049^{\mathrm{a}}$ \\
\hline $\mathrm{Z} \_\mathrm{RAD}_{i \tau}$ & $0.205^{\mathrm{a}}$ & 11.1 & $0.648^{b}$ & $0.012^{\mathrm{b}}$ & $0.057^{\mathrm{a}}$ & $\mathrm{Z}_{-} \triangle \mathrm{RAD}_{i \tau}$ & $0.147^{\mathrm{a}}$ & 9.1 & 0.527 & $0.012^{\mathrm{b}}$ & $0.066^{\mathrm{a}}$ \\
\hline $\mathrm{Z}_{-} \mathrm{C} 2_{i \tau}$ & $0.114^{\mathrm{a}}$ & 7.7 & 0.297 & 0.008 & $0.046^{\mathrm{a}}$ & $\mathrm{Z}_{-} \Delta \mathrm{C} 2_{i \tau}$ & $0.144^{\mathrm{a}}$ & 8.3 & $0.806^{\mathrm{a}}$ & $0.014^{\mathrm{a}}$ & $0.063^{\mathrm{a}}$ \\
\hline $\mathrm{Z} \__{\_} \mathrm{AD}_{i \tau}$ & 0.003 & 0.2 & 0.309 & 0.002 & 0.004 & $\mathrm{Z}_{-} \triangle \mathrm{AD}_{i \tau}$ & 0.008 & 0.2 & -0.127 & -0.001 & 0.001 \\
\hline \multirow[t]{3}{*}{$\mathrm{Z}_{-} \mathrm{PIN}_{i \tau}$} & $-0.222^{\mathrm{a}}$ & $-3.4-$ & $-0.855^{\mathrm{a}}$ & $-0.024^{\mathrm{a}}$ & $-0.056^{\mathrm{a}}$ & $\mathrm{Z}_{-} \triangle \mathrm{PIN}_{i \tau}$ & 0.097 & 1.3 & 0.152 & 0.008 & 0.012 \\
\hline & \multicolumn{5}{|c|}{ Panel C: ASY $_{i \tau}$-based deciles } & & \multicolumn{5}{|c|}{ Panel D: $\triangle \mathrm{ASY}_{i \tau}$-based deciles } \\
\hline & High-low $\beta$ & $n$-stat & $\rho^{\mathrm{SR}}$ & $b^{\mathrm{OLS}}$ & $\gamma$ & & High-low $\beta$ & ${ }_{n} t$-stat & $\rho^{\mathrm{SR}}$ & $b^{\mathrm{OLS}}$ & $\gamma$ \\
\hline$\beta_{1}$ & $0.410^{\mathrm{a}}$ & 3.4 & $0.612^{\mathrm{c}}$ & $0.030^{\mathrm{b}}$ & $0.068^{\mathrm{a}}$ & $\beta_{1}$ & $0.542^{\mathrm{a}}$ & 5.6 & $0.600^{\mathrm{c}}$ & $0.051^{\mathrm{b}}$ & $0.046^{\mathrm{a}}$ \\
\hline$\beta_{2}$ & $0.307^{\mathrm{a}}$ & 12.6 & $0.612^{\mathrm{c}}$ & $0.019^{\mathrm{b}}$ & $0.027^{\mathrm{a}}$ & $\beta_{2}$ & $0.243^{\mathrm{a}}$ & 12.8 & $0.733^{\mathrm{b}}$ & $0.018^{\mathrm{a}}$ & $0.034^{\mathrm{a}}$ \\
\hline$\beta_{3}$ & $-0.248^{\mathrm{a}}$ & $-9.4-$ & $-0.624^{c}$ & $-0.017^{\mathrm{a}}$ & $-0.017^{\mathrm{a}}$ & $\beta_{3}$ & $-0.191^{\mathrm{a}}$ & -9.7 & $-0.745^{\mathrm{b}}$ & $-0.014^{\mathrm{a}}$ & $-0.022^{\mathrm{a}}$ \\
\hline
\end{tabular}

Panels A and B report estimates for the difference between $\beta$ coefficients in Equation (1) for the highest and lowest information asymmetry deciles of firms based on either $\mathrm{ASY}_{i \tau}^{*}, \mathrm{Z}_{-} \mathrm{RAD}_{i \tau}, \mathrm{Z}_{-} \mathrm{C} 2_{i \tau}, \mathrm{Z} \_\mathrm{AD}_{i \tau}$, and Z_PIN ${ }_{i \tau}$ (i.e., levels) or $\triangle \mathrm{ASY}_{i \tau}^{*}, \mathrm{Z}_{-} \triangle \mathrm{RAD}_{i \tau}, \mathrm{Z}_{-} \triangle \mathrm{C} 2_{i \tau}, \mathrm{Z}_{-} \triangle \mathrm{AD}_{i \tau}$, and $\mathrm{Z}_{-} \mathrm{PIN}_{i \tau}$ (i.e., changes), as well as the coefficient $\gamma$ for an additional interaction term of $\mathrm{DEF}_{i \tau}$ and either $\mathrm{ASY}_{i \tau}$ or $\triangle \mathrm{ASY}_{i \tau}(\gamma)$ in Equation (1) (e.g., Equation (3)). Panels C and D report estimates for the coefficients $\beta_{n}$ in Equation (6) across deciles of firms sorted by either $\mathrm{ASY}_{i \tau}$ or $\triangle \mathrm{ASY} \mathrm{i}_{i \tau}$, as well as the coefficient $\gamma$ for an additional interaction term of $\mathrm{DEF}_{i \tau}$ and either $\operatorname{ASY}_{i \tau}$ or $\triangle \mathrm{ASY}_{i \tau}(\gamma)$ in Equation (6). a, b, c denote statistical significance at $1 \%, 5 \%$, and $10 \%$, respectively, assessed with (heteroskedasticity) robust standard errors adjusted for firm-level clustering; the resulting $t$-statistics are to the right of the corresponding estimate. $\rho^{\mathrm{SR}}$ and $b^{\mathrm{OLS}}$ are the Spearman rank correlation and linear regression coefficient, respectively, between the corresponding variable and either the $\mathrm{ASY}_{i \tau}$-based or the $\triangle \mathrm{ASY}_{i \tau}$-based rankings. 
Table A2

Further conventional leverage regressions

\begin{tabular}{|c|c|c|c|c|c|c|c|c|c|c|}
\hline \multirow[b]{2}{*}{ Equation (4) } & OLS & Tobit & OLS & OLS & OLS & \multirow[b]{2}{*}{ Equation (5) } & \multirow{2}{*}{$\frac{\text { OLS }}{(7)}$} & \multirow{2}{*}{$\frac{\text { OLS }}{(9)}$} & \multirow{2}{*}{$\frac{\text { OLS }}{(10)}$} & \multirow{2}{*}{$\frac{\text { OLS }}{(11)}$} \\
\hline & (1) & (2) & (4) & (5) & (6) & & & & & \\
\hline \multirow[t]{2}{*}{$\mathrm{ASY}_{i \tau}^{*}$} & $0.577^{\mathrm{a}}$ & $0.965^{\mathrm{a}}$ & $0.408^{\mathrm{a}}$ & $1.341^{\mathrm{a}}$ & $0.623^{\mathrm{a}}$ & $\triangle \mathrm{ASY}_{i \tau}^{*}$ & $0.220^{\mathrm{b}}$ & $0.203^{\mathrm{b}}$ & $0.179^{\mathrm{b}}$ & $0.214^{\mathrm{b}}$ \\
\hline & 7.6 & 9.7 & 7.7 & 7.8 & 8.2 & & 2.4 & 2.2 & 2.0 & 2.3 \\
\hline \multirow[t]{2}{*}{$\mathrm{Z} \_\mathrm{RAD}_{i \tau}$} & $-0.305^{\mathrm{a}}$ & $-0.912^{\mathrm{a}}$ & $-0.255^{\mathrm{a}}$ & $-0.412^{\mathrm{b}}$ & $-0.298^{a}$ & $\mathrm{Z}_{-} \triangle \mathrm{RAD}_{i \tau}$ & $-0.071^{\mathrm{c}}$ & -0.049 & -0.055 & $-0.083^{b}$ \\
\hline & -6.2 & -13.7 & -5.3 & -2.2 & -6.0 & & -1.8 & -1.3 & -1.4 & -2.1 \\
\hline \multirow[t]{2}{*}{$\mathrm{Z}_{-} \mathrm{C} 2_{i \tau}$} & $0.201^{\mathrm{a}}$ & $0.432^{\mathrm{a}}$ & $0.232^{\mathrm{a}}$ & $0.596^{\mathrm{b}}$ & $0.210^{\mathrm{a}}$ & $\mathrm{Z}_{-} \Delta \mathrm{C} 2_{i \tau}$ & 0.0003 & 0.073 & -0.019 & -0.0009 \\
\hline & 3.9 & 5.2 & 4.6 & 2.1 & 4.2 & & 0.01 & 0.2 & -0.5 & -0.02 \\
\hline \multirow[t]{2}{*}{ Z_AD ${ }_{i \tau}$} & 0.025 & 0.145 & $0.192^{b}$ & $0.195^{\mathrm{c}}$ & 0.031 & $\mathrm{Z}_{-} \Delta \mathrm{AD}_{i \tau}$ & 0.089 & 0.083 & 0.119 & 0.089 \\
\hline & 0.3 & 1.2 & 2.2 & 1.8 & 0.4 & & 1.0 & 0.9 & 1.3 & 1.0 \\
\hline \multirow[t]{2}{*}{$\mathrm{Z} \_P I N_{i \tau}$} & $0.480^{\mathrm{b}}$ & $2.164^{\mathrm{a}}$ & 0.306 & 0.367 & $0.470^{\mathrm{b}}$ & $\mathrm{Z}_{-} \triangle \mathrm{PIN}_{i \tau}$ & $0.178^{\mathrm{c}}$ & $0.183^{\mathrm{c}}$ & $0.187^{\mathrm{c}}$ & $0.186^{\mathrm{c}}$ \\
\hline & 2.3 & 8.8 & 1.5 & 0.8 & 2.3 & & 1.8 & 1.8 & 1.9 & 1.9 \\
\hline
\end{tabular}

This table reports estimates for the coefficient $b_{1}$ from firm fixed effects and Tobit panel regressions of Equation (4) for Leverage ${ }_{i \tau}=\mathrm{DMA}_{i \tau}$, where we replace $\mathrm{ASY}_{i \tau}$ with $\mathrm{ASY}_{i \tau}^{*}, \mathrm{Z}_{-} \mathrm{RAD}_{i \tau}, \mathrm{Z}_{-} \mathrm{C} 2_{i \tau}, \mathrm{Z}_{-} \mathrm{AD}_{i \tau}$, or $\mathrm{Z}_{-} \mathrm{PIN} \mathrm{N}_{i \tau}$ (i.e., levels), and from fixed effects regressions of Equation (5) for $\triangle$ Leverage $_{i \tau}=\triangle \mathrm{DMA}_{i \tau}$, where we replace $\triangle \mathrm{ASY} \mathrm{Y}_{i \tau}$ with $\triangle \mathrm{ASY}_{i \tau}^{*}, \mathrm{Z}_{-} \triangle \mathrm{RAD}_{i \tau}, \mathrm{Z}_{-} \triangle \mathrm{C} 2_{i \tau}, \mathrm{Z}_{-} \triangle \mathrm{AD}_{i \tau}$, or $\mathrm{Z}_{-} \triangle \mathrm{PIN} \mathrm{N}_{i \tau}$ (i.e., changes). The column number in parentheses refers to the corresponding regression specification in Table 6. a, b, c denote statistical significance at $1 \%, 5 \%$, and $10 \%$, respectively, assessed with (heteroskedasticity) robust standard errors adjusted for firm-level clustering; the resulting $t$-statistics are reported below the estimates for $b_{1}$. Each estimate is multiplied by 100 .

\section{References}

Aboody, D., and B. Lev. 2000. Information Asymmetry, R\&D, and Insider Gains. Journal of Finance 55:2747-66.

Agarwal, P., and M. O'Hara. 2006. Information Risk and Capital Structure. Working Paper, Cornell University.

Alford, A., and P. Jones. 2003. A Simultaneous Equations Analysis of Forecast Accuracy, Analyst Following, and Trading Volume. Journal of Accounting, Auditing, and Finance 14:219-40.

Amihud, Y. 2002. Illiquidity and Stock Returns: Cross Section and Time-Series Effects. Journal of Financial Markets 5:31-56.

Amihud, Y., and H. Mendelson. 1980. Dealership Market: Market Making with Inventory. Journal of Financial Economics 8:311-53.

Amihud, Y., H. Mendelson, and B. Lauterbach. 1997. Market Microstructure and Securities Value: Evidence from the Tel Aviv Exchange. Journal of Financial Economics 45:365-90.

Bagehot, W. 1971. The Only Game in Town. Financial Analyst Journal 27:12-22.

Barclay, M., and C. Smith. 1995a. The Maturity Structure of Debt. Journal of Finance 50:609-31.

Barclay, M., and C. Smith. 1995b. The Priority Structure of Corporate Liabilities. Journal of Finance 50:899-918.

Bayless, M., and S. Chaplinsky. 1996. Is There a Window of Opportunity for Seasoned Equity Issuance? Journal of Finance 51:253-78.

Berger, A., and G. Udell. 1995. Relationship Lending and Lines of Credit in Small Firm Finance. Journal of Business 68:351-81.

Best, R., C. Hodges, and B. Lin. 2004. Does Information Asymmetry Explain the Diversification Discount? Journal of Financial Research 27:235-349.

Brennan, M., and A. Subrahmanyam. 1995. Investment Analysis and Price Formation in Securities Markets. Journal of Financial Economics 38:361-81.

Chae, J. 2005. Timing Information, Information Asymmetry, and Trading Volume. Journal of Finance 60:413-42. 
Chang, X., S. Dasgupta, and G. Hilary. 2006. Analyst Coverage and Financing Decisions. Journal of Finance 61:3009-48.

Chen, Q., I. Goldstein, and W. Jiang. 2007. Price Informativeness and Investment Sensitivity to Stock Price. Review of Financial Studies 20:619-50.

Chirinko, R., and A. Singha. 2000. Testing Static Tradeoff Against Pecking Order Models of Capital Structure: A Critical Comment. Journal of Financial Economics 58:417-25.

Choe, H., R. Masulis, and V. Nanda. 1993. Common Stock Offerings Across the Business Cycle. Journal of Empirical Finance 1:3-31.

Clarke, J., and K. Shastri. 2001. On Information Asymmetry Metrics. Working Paper, University of Pittsburgh.

Cooper, S., J. Groth, and W. Avera. 1985. Liquidity, Exchange Listing, and Stock Return Performance. Journal of Economics and Business 37:19-33.

Desai, A., M. Nimalendran, and V. Venkataraman. 1998. Changes in Trading Activity Following Stock Splits and Their Effect on Volatility and the Adverse Information Component of the Bid-Ask Spread. Journal of Financial Research 21:159-83.

Dierkens, N. 1991. Information Asymmetry and Equity Issues. Journal of Financial and Quantitative Analysis 26:181-99.

Diether, K., C. Malloy, and A. Scherbina. 2002. Differences of Opinion and the Cross Section of Stock Returns. Journal of Finance 57:2113-41.

Easley, D., S. Hvidkjaer, and M. O'Hara. 2004. Factoring Information into Returns. Working Paper, University of Maryland.

Easley, D., N. Kiefer, and M. O'Hara. 1996. Cream-Skimming or Profit-Sharing? The Curious Role of Purchased Order Flow. Journal of Finance 51:811-33.

Easley, D., N. Kiefer, and M. O'Hara. 1997a. The Information Content of the Trading Process. Journal of Empirical Finance 4:159-86.

Easley, D., N. Kiefer, and M. O'Hara. 1997b. One Day in the Life of a Very Common Stock. Review of Financial Studies 10:805-35.

Easley, D., N. Kiefer, M. O’Hara, and J. Paperman. 1996. Liquidity, Information, and Infrequently Traded Stocks. Journal of Finance 51:1405-36.

Fama, E., and K. French. 2002. Testing Trade-Off and Pecking Order Predictions About Dividends and Debt. Review of Financial Studies 15:1-33.

Fama, E., and K. French. 2005. Financing Decisions: Who Issues Stock? Journal of Financial Economics 76:549-82.

Flannery, M., S. Kwan, and M. Nimalendran. 2004. Market Evidence on the Opaqueness of Banking Firms' Assets. Journal of Financial Economics 71:419-60.

Frank, M., and V. Goyal. 2003. Testing the Pecking Order Theory of Capital Structure. Journal of Financial Economics 67:217-48.

Frankel, R., and X. Li. 2004. The Characteristics of a Firm's Information Environment and the Information Asymmetry Between Insiders and Outsiders. Journal of Accounting and Economics 37:229-59.

Frieder, L., and R. Martell. 2005. On Capital Structure and the Liquidity of a Firm's Stock. Working Paper, Purdue University.

George, T., G. Kaul, and M. Nimalendran. 1991. Estimation of the Bid-Ask Spread and Its Components: A New Approach. Review of Financial Studies 4:623-56.

Gomes, A., and G. Phillips. 2005. Why Do Public Firms Issue Private and Public Securities? Working Paper 11294, NBER. 
Graham, J., J. Koski, and U. Loewenstein. 2006. Information Flow and Liquidity Around Anticipated and Unanticipated Dividend Announcements. Journal of Business 79:2301-36.

Halov, N., and F. Heider. 2004. Capital Structure, Risk, and Asymmetric Information. Working Paper, New York University.

Harris, M., and A. Raviv. 1991. The Theory of Capital Structure. Journal of Finance 46:297-355.

Hasbrouck, J. 1991. Measuring the Information Content of Stock Trades. Journal of Finance 46:179-207.

Hasbrouck, J. 2005. Trading Costs and Returns for U.S. Equities: The Evidence from Daily Data. Working Paper, New York University.

Hasbrouck, J. 2006. Empirical Market Microstructure: The Institutions, Economics and Econometrics of Securities Trading. New York, NY: Oxford University Press.

Heflin, F., and K. Shaw. 2000. Blockholder Ownership and Market Liquidity. Journal of Financial and Quantitative Analysis 35:621-33.

Heflin, F., K. Shaw, and J. Wild. 2005. Disclosure Quality and Market Liquidity: Impact of Depth Quotes and Order Sizes. Contemporary Accounting Research 22:829-65.

Huang, R., and H. Stoll. 1997. The Components of the Bid-Ask Spread: A General Approach. Review of Financial Studies 10:995-1034.

Huddart, S., and B. Ke. 2007. Information Asymmetry and Cross-Sectional Variation in Insider Trading. Contemporary Accounting Research 24:195-232.

Jegadeesh, N., and A. Subrahmanyam. 1993. Liquidity Effects of the Introduction of the S\&P 500 Index Futures Contract on the Underlying Stocks. Journal of Business 66:171-87.

Jennings, R. 1994. Intraday Changes in Target Firms' Share Price and Bid-Ask Quotes Around Takeover Announcements. Journal of Financial Research 17:215-70.

Korajczyk, R., D. Lucas, and R. MacDonald. 1991. The Effect of Information Releases on the Pricing and Timing of Equity Issues. Review of Financial Studies 4:695-708.

Krishnaswami, S., and V. Subramaniam. 1999. Information Asymmetry, Valuation, and the Corporate Spin-off Decision. Journal of Financial Economics 53:73-112.

Kumar, R., A. Sarin, and K. Shastri. 1998. The Impact of Options Trading on the Market Quality of the Underlying Security: An Empirical Analysis. Journal of Finance 53:717-32.

Kyle, A. 1985. Continuous Auctions and Insider Trading. Econometrica 53:1315-35.

Lakonishok, J., and I. Lee. 2001. Are Insider Trades Informative? Review of Financial Studies 14:79-111.

Leary, M., and M. Roberts. 2004. Financial Slack and Tests of the Pecking Order's Financing Hierarchy. Working Paper, Duke University.

Lee, C., B. Mucklow, and M. Ready. 1993. Spreads, Depths, and the Impact of Earnings Information: An Intraday Analysis. Review of Financial Studies 6:345-74.

Lemmon, M., and J. Zender. 2004. Debt Capacity and Tests of Capital Structure Theories. Working Paper, University of Colorado.

Lipson, M., and S. Mortal. 2006. Capital Structure Decisions and Equity Market Liquidity. Working Paper, University of Virginia.

Llorente, G., R. Michaely, G. Saar, and J. Wang. 2002. Dynamic Volume-Return Relation of Individual Stocks. Review of Financial Studies 15:1005-47.

Marsh, P. 1982. The Choice Between Equity and Debt: An Empirical Study. Journal of Finance 37:121-44.

Myers, S. 1984. The Capital Structure Puzzle. Journal of Finance 39:575-92. 
Myers, S. 2001. Capital Structure. Journal of Economic Perspectives 15:81-102.

Myers, S., and N. Majluf. 1984. Corporate Financing and Investment Decisions When Firms Have Information That Investors Do Not Have. Journal of Financial Economics 13:187-221.

Neal, R., and S. Wheatley. 1998. Adverse Selection and Bid-Ask Spreads: Evidence from Closed-End Funds. Journal of Financial Markets 1:121-49.

Odders-White, E., and M. Ready. 2006. Credit Ratings and Stock Liquidity. Review of Financial Studies 19:11957.

O’Hara, M. 1995. Market Microstructure Theory. Malden, MA: Blackwell.

Pasquariello, P., and C. Vega. 2007. Informed and Strategic Order Flow in the Bond Markets. Review of Financial Studies 20:1975-2019.

Pastor, L., and R. Stambaugh. 2003. Liquidity Risk and Expected Stock Returns. Journal of Political Economy 111:642-85.

Rajan, R., and L. Zingales. 1995. What Do We Know About Capital Structure: Some Evidence from International Data. Journal of Finance 50:1421-60.

Roll, R. 1984. A Simple Implicit Measure of the Effective Bid-Ask Spread in an Efficient Market. Journal of Finance 39:1127-39.

Sadka, R., and A. Scherbina. 2007. Analyst Disagreement, Mispricing, and Liquidity. Journal of Finance 62:2367-03.

Serednyakov, A. 2002. The Information Flows Around Bankruptcy Announcements: An Empirical Investigation. Working Paper, University of Minnesota.

Seyhun, N. 1986. Insiders' Profits, Costs of Trading, and Market Efficiency. Journal of Financial Economics 16:189-212.

Shyam-Sunder, L., and S. Myers. 1999. Testing Static Tradeoff Against Pecking Order Models of Capital Structure. Journal of Financial Economics 51:219-44.

Stoll, H. 1978. The Supply of Dealer Services in Securities Markets. Journal of Finance 33:1133-51.

Taggart, R. 1977. A Model of Corporate Financing Decisions. Journal of Finance 32:1467-84. 